Provided for non-commercial research and education use. Not for reproduction, distribution or commercial use.

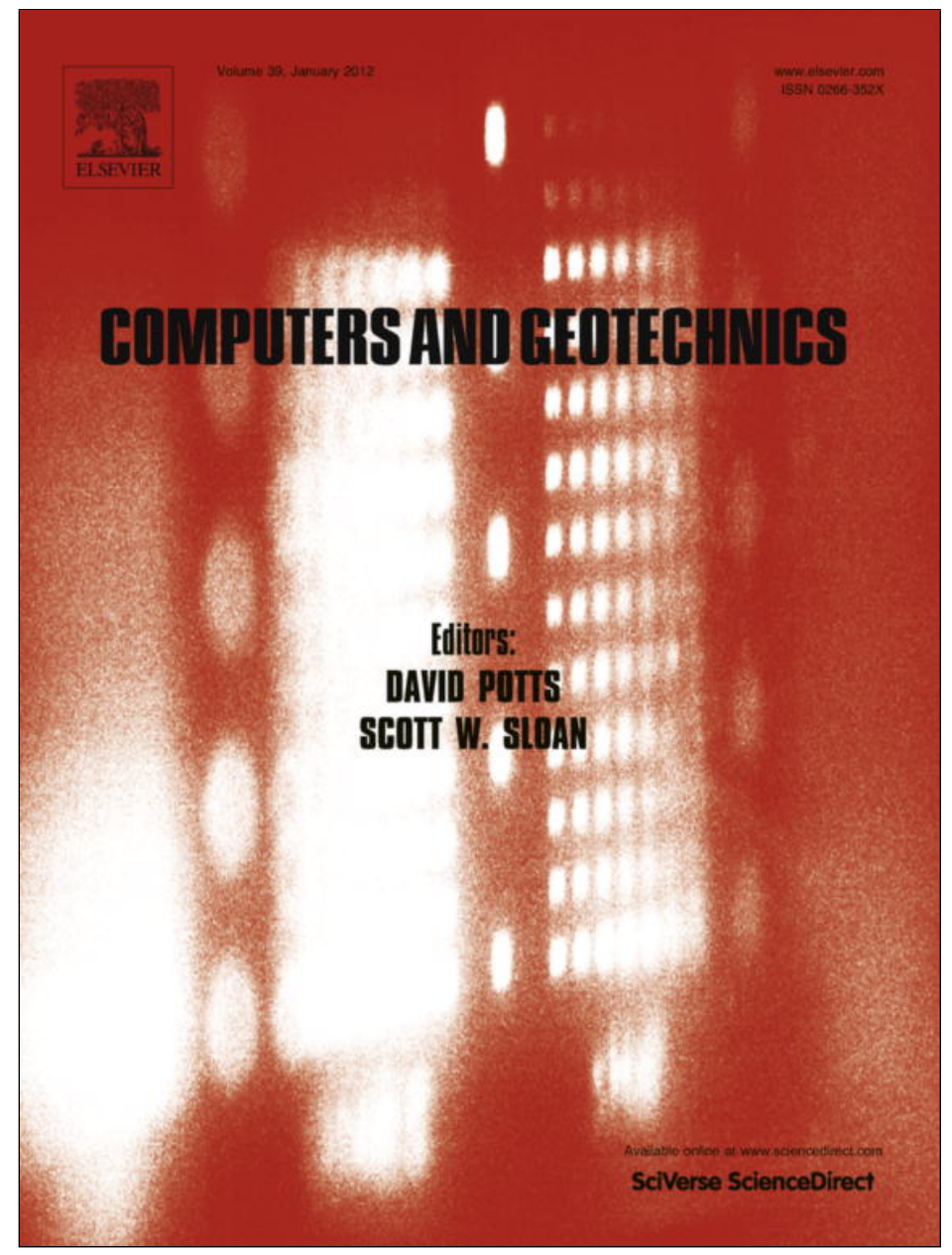

(This is a sample cover image for this issue. The actual cover is not yet available at this time.)

This article appeared in a journal published by Elsevier. The attached copy is furnished to the author for internal non-commercial research and education use, including for instruction at the authors institution and sharing with colleagues.

Other uses, including reproduction and distribution, or selling or licensing copies, or posting to personal, institutional or third party websites are prohibited.

In most cases authors are permitted to post their version of the article (e.g. in Word or Tex form) to their personal website or institutional repository. Authors requiring further information regarding Elsevier's archiving and manuscript policies are encouraged to visit:

http://www.elsevier.com/copyright 


\title{
A bio-chemo-hydro-mechanical model for microbially induced calcite precipitation in soils
}

\author{
S. Fauriel*, L. Laloui \\ Soil Mechanics Laboratory, Swiss Federal Institute of Technology, EPFL-ENAC-LMS, Station 18, 1015 Lausanne, Switzerland
}

\section{A R T I C L E I N F O}

\section{Article history:}

Received 5 January 2012

Received in revised form 16 May 2012

Accepted 29 May 2012

\section{Keywords:}

Biogrout

MICP

Coupled model

Numerical treatment

\begin{abstract}
A B S T R A C T
Microbially Induced Calcite Precipitation (MICP) is an innovative technique for soil grouting involving a bacterial reactive grout. This comprehensive research study is carried out to better understand and describe the coupled phenomena of multispecies reactive biogrout transport in a saturated, deformable soil. A unique predictive model of the behaviour of the porous media during biogrout injection is presented. The general field equations describing the system are derived from the macroscopical balance equations and constitutive equations. The set of field equations is numerically discretised. Finally, numerical examples are provided as a first step to validate the capabilities of the proposed model.
\end{abstract}

(C) 2012 Elsevier Ltd. All rights reserved.

\section{Introduction}

Calcite precipitation can occur naturally when there is an excess of calcium ions in a solution. However, bacterial strains producing urease can have a considerable impact on the precipitation process if they are supplied with calcium and urea. By temporarily regulating the concentration of bacteria and nutrients in a soil, a new engineering material can be generated through bacterially induced calcite cementation of the existent soil matrix. This approach can be used to decrease the permeability and the compressibility of the soil and increase the strength of the soil.

Understanding, controlling and predicting this alternative environmentally friendly soil reinforcement technique enables many geo-engineering problems to be reconsidered and exposes innovative applications, such as restoration of weak foundations, seismic retrofitting, erosion protection and construction of floating beaches. MICP has been experimentally investigated during the past decade by several researchers [1-9], yielding a reasonable level of understanding of the involved processes. However, the prediction of MICP is still relatively unexplored, with the exception of the recently published developments by Martinez et al. [10] and van Wijngaarden et al. [11]. Thus, there is a clear need to further develop comprehensive bio-chemo-hydro-mechanical (BCHM) mathematical modelling capacities that are able to realistically predict the multispecies reactive transport in saturated, deformable soils.

\footnotetext{
* Corresponding author. Tel.: +41 2169323 13; fax: +41 216934153 .

E-mail address: suzanne.chalindar@epfl.ch (S. Fauriel).
}

The objective of this paper is to develop a general mathematical model to describe the injection, the distribution and the reaction processes of biogrout within a saturated, deformable porous medium. The consequences of sorption and reaction on the solid matrix composition are also considered. The model is entirely defined by the flow, the equilibrium and the transport equations, which are described in a thermodynamically consistent framework. The theoretical treatment of the MICP-treated porous media is based on the averaging approach proposed by Bear and Bachmat [12]. The complex bio-chemo-mechanical coupling involved in MICP is discussed in detail in Fauriel and Laloui [13] and a simplified stress-strain framework is thus adopted in the present model formulation.

\section{Background}

\subsection{Biogrouting}

There has long been interest in bacterially promoted calcium carbonate precipitation, particularly in marine systems because of the obvious role that bacteria play in the carbon cycle through the biomineralisation of carbonates [14]. Furthermore, the interest in this process has greatly increased recently for applications such as restoration of calcareous stone materials, bioremediation, wastewater treatment, concrete strengthening and selective plugging for enhanced oil recovery [6].

Biogrouting is based on the injection of an urease-producing bacteria, typically Sporosarcina pasteurii, into the soil. First, the bacteria need to be cultivated in the laboratory, yielding a target con- 
centration and a target activity, which both depend on the application, keeping in mind that the bacteria decay and their activity decrease during the injection. The transport of the bacteria to the targeted location in the soil is typically controlled by gravity liquid flow or pumping. The diffusion and the dispersion of the bacteria with respect to the advective transport are also expected. The bacteria are then left in the soil to attach to the solid grains. The accumulation of the bacteria at the grain surface can slightly alter the solid phase volume, affecting the porosity and the permeability. Finally, the nutrients required for the chemical precipitation to occur (i.e., urea and calcium) are injected at a given concentration. The transport of the nutrients is governed by advection, diffusion and dispersion. Additionally, the nutrients can attach and detach from the solid grains, changing the fluid density. The fluid density changes can sometimes cause density-driven flow. The bacterially catalysed chemical reaction causes the concentrations of urea and calcium to decrease in the presence of urease, and ammonium is produced at a rate that depends on the bacterial concentration, the specific urease activity and the urea concentration. Calcite is also precipitated, a significant amount of which attaches to the solid grains, reducing both the porosity and the permeability of the soil and increasing both the strength and the stiffness of the soil. During the injection process, the mechanically induced volume changes may affect the fluid flow. Reversely, the effective stress changes related to the pore pressure variations can be very important due to the non-negligible porosity variations upon calcite precipitation.

The major limitation of the MICP process is related to the material pore size. The minimum pore size in which bacteria can move freely ranges from 0.5 to $2 \mu \mathrm{m}$ [15]. The MICP is thus assumed to only be efficient in silts, fine sands or coarser material. In addition, secondary microbial products are produced during the metabolic activity of the bacteria (e.g., ammonia during the hydrolysis of urea). All of the residual products of the MICP process should be removed from the soil or converted to neutral products such as water, carbon dioxide and nitrogen gas [15], complicating the in situ process. In the field, the application of MICP is limited by its low injection rate, which might cause the cementation process to start during the injection phase. These processes are similar to those of the micro-cement injection in soils [16].

\subsection{Microbially Induced Calcite Precipitation}

In natural environments, the primary means by which microorganisms promote calcium carbonate precipitation is by metabolic processes that increase the alkalinity of the soil. In MICP, by way of urea hydrolysis, bacteria processing the enzyme urease can use urea $\left(\left(\mathrm{NH}_{2}\right)_{2} \mathrm{CO}\right)$ as an energy source and produce ammonium $\left(\mathrm{NH}_{4}^{+}\right)$. More specifically, the hydrolysis of urea is catalysed by urease, producing ammonium and carbonate ions $\left(\mathrm{CO}_{3}^{2-}\right)$ according to Eq. (1). Ammonium then dissociates to ammonia $\mathrm{NH}_{3}$ as a result of the $\mathrm{pH}$ increase, until equilibrium between $\mathrm{NH}_{4}^{+} / \mathrm{NH}_{3}$ and $\mathrm{HCO}_{3}^{-} / \mathrm{CO}_{3}^{2-}$ is reached at a pH of approximately 9.3 [7]. The hydrolysis of urea is a homogeneous reaction that takes place within the fluid phase, causing mass transfer among the components of the fluid phase shown below.

$\mathrm{CO}\left(\mathrm{NH}_{2}\right)_{2}+2 \mathrm{H}_{2} \mathrm{O} \stackrel{\text { urease }}{\rightarrow} 2 \mathrm{NH}_{4}^{+}+\mathrm{CO}_{3}^{2-}$

Upon hydrolysis of urea, the products of Eq. (1) further react into a wide range of dissolved species, including carbonate, bicarbonate $\left(\mathrm{HCO}_{3}^{-}\right)$, carbonic acid $\left(\mathrm{H}_{2} \mathrm{CO}_{3}\right)$, hydroxide $\left(\mathrm{OH}^{-}\right)$and protons $\left(\mathrm{H}^{+}\right)$. In the presence of calcium ions $\left(\mathrm{Ca}^{2+}\right)$, dissolved complexes can form with the anions (e.g., calcium carbonate $\left(\mathrm{CaCO}_{3}\right)$ ). This speciation is governed by acid-base equilibria and depends on $\mathrm{pH}$, temperature and salinity [7].
Finally, the last reaction type involved in MICP is mineralisation. The mineralisation itself consists of several phases characterised by different rates: nucleation, crystal growth and secondary changes in the crystal lattice. If a sufficient amount of carbonate is produced, then the solution becomes oversaturated, and calcium carbonate can precipitate (Eq. (2)). Eq. (2) corresponds to a heterogeneous precipitation reaction, which adds mass to the matrix [17].

$\mathrm{CO}_{3}^{2-}+\mathrm{Ca}^{2+} \rightarrow \mathrm{CaCO}_{3(s)}$

\subsection{Relevant modelling frameworks}

In this section, the most representative transport models dealing with some of the processes involved in MICP are reviewed. Transport models for conventional grouts, bacteria, contaminants, reactive chemicals and biogrout are non-exhaustively reviewed.

In the most recent studies on advanced grouting fluid transport analysis [18-21], filtration is a key element in these mathematical formulations. Bouchelaghem and Vulliet [18] also consider a deformable soil, as well changing permeability, density and viscosity following the grout injection.

Because bacteria are living organisms, they are subjected to mechanisms that influence the transport and the removal of microbes in saturated, porous media as well as physico-chemical phenomena. The mathematical models for bacteria-enriched fluid transport models of varying complexity have been proposed, and these models typically involve a simplified form of the advection-dispersion equation [22-27]. In this model category, the works of Schijven and co-workers [28-32] dealing with kinetic modelling of virus transport are also noteworthy.

The advanced pollutant transport models, such as the one developed by Biver [33], combine the flow and the contaminant transport equations. Biver [33] developed a finite element formulation in the Lagamine code to solve an advection-dispersion equation with sorption and degradation effects.

Reactive transport modelling is an essential tool for analysing coupled physical, chemical and biological processes [34]. The first reactive transport studies were published in the mid-eighties by Lichtner [35]. A number of reactive transport models were later proposed [36-39].

To the best of the authors' knowledge, only two biogrout transport models have been presented in the literature. Martinez et al. [10] proposed a microbially mediated calcite precipitation model, which they built into a numerical simulation program for the chemically reactive flow of multiphase fluids in porous media (THOUGHREACT). They incorporated a comprehensive reaction network created in a computer program for speciation, batch-reaction, one-dimensional transport and inverse geochemical calculations (PHREEQCII) into the transport simulator. The model included and dissolution/exsolution, kinetic calcite mineral precipitation/dissolution and ureolysis. The transport of bacteria was not considered, and the initial concentration of the urease component was estimated by optimising the TOUGHREACT model with UCODE using $\mathrm{pH}$ data from batch experiments. A biogrout model was recently proposed by van Wijngaarden et al. [11]. A perfectly miscible fluid with variable porosity, permeability and density was considered. An overall biogrout reaction consisting of instantaneous sorption and precipitation was assumed. Bacteria were not considered in the model, but the catalysing ability of the bacteria was mimicked by a linearly decreasing, homogeneous urease activity included in the reaction rate. A rigid body was considered in the model.

The state-of-the-art modelling of MICP-treated soils reveals the scarcity of appropriate modelling tools. Furthermore, most existing models do not address the mechanical issues and the double-way 
couplings between the mechanics and the bio-chemo-hydraulics. Thus, a comprehensive, bio-chemo-hydro-mechanical (BCHM), conceptual, mathematical model that is able to realistically predict the involved processes and the overall system response is needed.

\section{Theoretical framework}

\subsection{System definition}

In the considered problem, the porous medium is assumed to be fully saturated with one fluid phase. The injected bacteria are expected to stay suspended in the fluid phase or adsorb onto the minerals of the solid matrix. Similarly, the chemical reactants (urea and calcium, which will be considered a single species with an equivalent molar mass because they are assumed to be injected equimolarly and react equimolarly) can be either solute or sorbed. The ammonium can also exist in both phases. The calcite is assumed to instantaneously attach to the solid matrix upon the precipitation and is therefore not present in the fluid phase. The Representative Elementary Volume (REV) of the considered system is thus composed of the following components (shown in Fig. 1):

- The solid phase denoted by subscript $s$ contains five components denoted by subscripts: solid grains $(g)$, sorbed bacteria $(b)$, sorbed urea/calcium $(r)$, sorbed ammonium $(p)$ and calcite (c).

- The fluid phase denoted by subscript $f$ contains four components by a subscript: pore water $(w)$, solute bacteria $(b)$, solute urea/calcium $(r)$ and solute ammonium $(p)$.

\subsection{Considered processes}

With respect to the existing models listed in Section 2.3, the proposed BCHM model consists in a unified system of equations that allows all of the major processes involved in MICP described in Section 2.1 to be considered. The following bio-chemo-hydromechanical mechanisms and their couplings, which are summarised in Fig. 2, are taken into account:

- Mechanisms governing the flow of the fluid phase: the advective flow, the porosity and the permeability changes due to the mechanical stress, the bacterial accumulation on the solid grains and the calcite precipitation and the fluid phase density changes due to the changing fluid composition.

- Mechanisms governing the equilibrium of the mixture: the stress-strain relationship, the effective stress changes due to the changing fluid pressure fields, the stiffness changes due to the chemical cementation of the soil matrix and the solid phase density changes due to the changing solid phase composition.

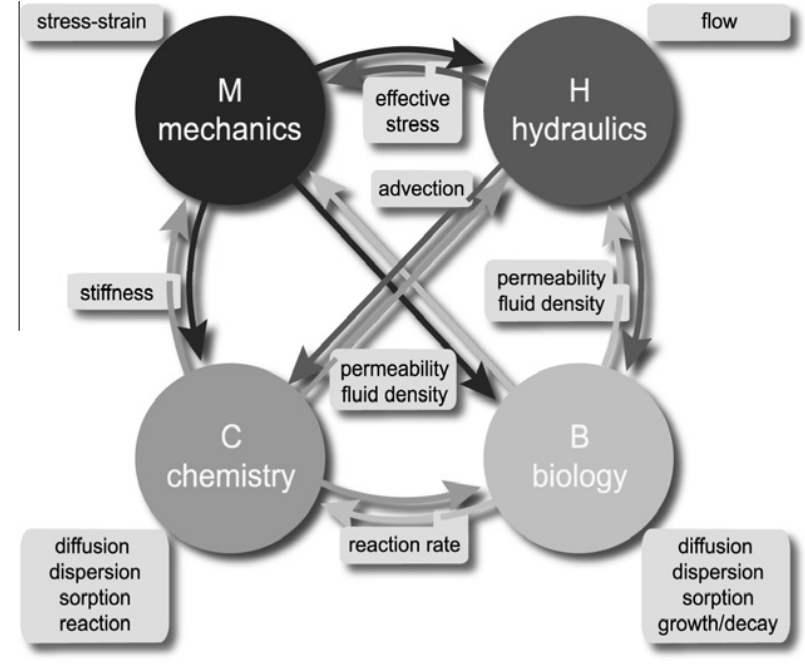

Fig. 2. BCHM mechanisms and their couplings.

- Mechanisms governing the transport of the components: the advection, the diffusion, the dispersion, the sorption, the bacterial decay in both of the phases, the advective flux changes due to the changing fluid pressure fields, the biologically catalysed chemical reaction responsible for the consumption of urea/calcium and the production of ammonium, the porosity changes due to the mechanical stress, the bacterial accumulation on the solid grains and the calcite precipitation.

\section{Mathematical model}

\subsection{Balance equations}

Because the velocity distribution within the fluid phase is needed as input information for the component transport problem and the bio-chemo-hydro-mechanical couplings are taken into account, the mass balance of the fluid and solid phases carrying the bacteria and the chemical components and the momentum balance of the mixture are needed. Thus, the balance equations required in the development of the model are as follows:

- Solid phase and fluid phase mass balance to evaluate the porosity changes and the velocity distribution through a flow equation.

- Mixture momentum balance.

- Component mass balance to derive the transport equations.

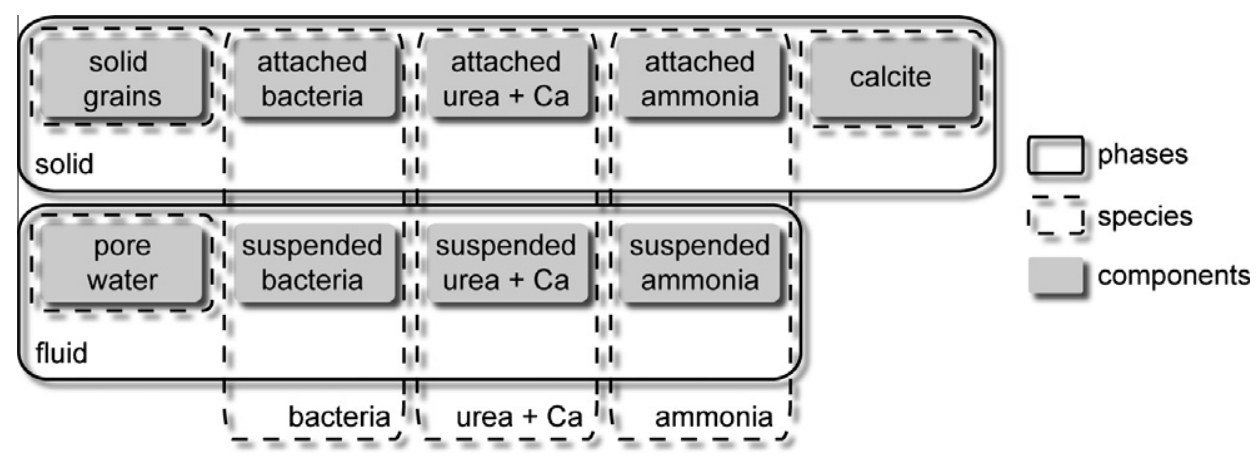

Fig. 1. Phases, components and species. 
In light of the required balance equations, the compositional approach [40] is appropriate. First, the balance of each component is expressed referring to the assumptions listed in the appendix, from which all of the necessary equations are derived.

The general balance equation of an extensive quantity $E$ of density $e$ within a control domain $U$ (where $S$ is the area of the surface that is bonding it) can be expressed by the following [12]: urea/calcium and sorbed ammonium are negligible with respect to the volume of calcite. Thus, molar concentrations can be used to describe these components.

The mass balance for all of the solid phase components yield the following equations for the solid grains, the sorbed bacteria, the calcite, the sorbed calcium/urea and the sorbed ammonium, respectively:

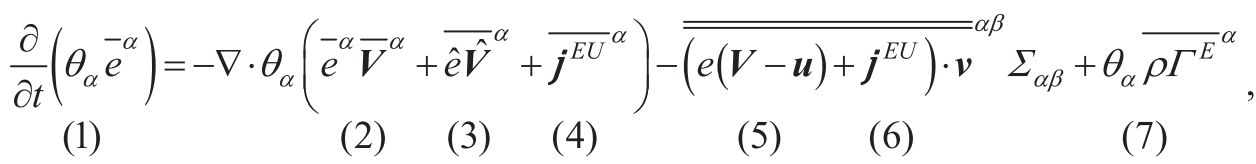

where $\theta_{\alpha}$ is the volume fraction of phase $\alpha ; \boldsymbol{V}$ is the phase velocity; $\boldsymbol{j}^{E U}$ is the diffusive flux of $E$ defined as $\boldsymbol{j}^{E U}=e^{\alpha}\left(\boldsymbol{V}^{E}-\boldsymbol{V}\right) ; \boldsymbol{u}$ is the surface velocity; $v$ is the outward normal unit vector on $S_{\alpha \beta} ; \Sigma_{\alpha \beta}$ is the specific area of surface $S_{\alpha \beta}$; and $\rho$ is the mass density and $\Gamma^{E}$ is the rate of production of $E$ per unit mass of the phase. The volumetric intrinsic phase density $\bar{e}^{\alpha}$ is defined as $\bar{e}^{\alpha}=\frac{1}{U_{0 \alpha}} \int_{\mathrm{U}_{0}}$ edU. The deviation of a quantity $\hat{e}$ with respect to its intrinsic phase average is expressed as $\hat{e}=e-\bar{e}^{\alpha}$ and the surface average $\bar{e}^{\alpha \beta}$ is defined as follows $\overline{\bar{e}}^{\alpha \beta}=\frac{1}{S_{\alpha \beta}} \int_{S_{\alpha \beta}}$ edS.

The contributions to the general balance equations (Eq. (3)) are as follows:

(1) Rate of increase in $E$ in the phase (per unit volume of porous media).

(2) Net influx of $E$ by averaged advection (per unit volume of porous media).

(3) Net influx of $E$ by averaged dispersion (per unit volume of porous media).

(4) Net influx of $E$ by averaged diffusion (per unit volume of porous media).

(5) Net influx of $E$ through the interface surface $S_{\alpha \beta}$ of the phase by advection with respect to the (possibly moving) $S_{\alpha \beta}$ surface (per unit volume of porous media).

(6) Net influx of $E$ through the interface surface $S_{\alpha \beta}$ of the phase by diffusion with respect to the (possibly moving) $S_{\alpha \beta}$ surface (per unit volume of porous media).

(7) Net rate of production of $E$ generated by sources of $E$ (per unit volume of porous media).

\subsubsection{Mass balance}

Before developing the mass balance equations for all of the system components, the macroscopical mass balance equation of a component, where $E=m^{\gamma}, e=\rho^{m^{\gamma}} \equiv \rho^{\gamma}, j^{E U}=j^{m^{\gamma}} \equiv j^{\gamma} \quad$ and $\Gamma^{E}=\Gamma^{m^{\gamma}}$, is shown below in a more concise form [12]:

$\frac{\partial}{\partial t}\left(\theta_{\alpha} \rho_{\alpha}^{\gamma}\right)=-\nabla \cdot \theta_{\alpha}\left(\rho_{\alpha}^{\gamma} \boldsymbol{V}_{\alpha}+\boldsymbol{j}_{\alpha}^{* \gamma}\right)-\Lambda_{\alpha \beta}^{\gamma}+\Omega_{\alpha}^{\gamma}$,

where $\boldsymbol{j}_{\alpha}^{* \gamma}=\overline{\hat{\rho}}^{\gamma} \widehat{\boldsymbol{V}}^{\alpha}+\boldsymbol{j}_{\alpha}^{\gamma}$ is the hydrodynamic dispersion flux defined as the sum of the dispersive and the diffusive fluxes, $\Lambda_{\alpha \beta}^{\gamma}=\overline{\overline{\left(\rho^{\gamma}(\boldsymbol{V}-\boldsymbol{u})+\boldsymbol{j}^{\gamma}\right) \cdot \boldsymbol{v}^{\alpha \beta}}} \Sigma_{\alpha \beta}$ is the net influx of component $\gamma$ into phase $\alpha$ and $\Omega_{\alpha}^{\gamma}=\theta \overline{\rho \Gamma^{m^{\gamma}} \alpha}$ is the net production rate of component $\gamma$ within phase $\alpha$.

Mass balance of the solid phase. In the solid phase, the components remain physically separated, and local volume fractions can be used to define the volumetric phase average of density $\rho_{\alpha}^{\gamma}=\kappa_{\alpha}^{\gamma} \rho^{\gamma}$ where $\kappa_{\alpha}^{\gamma}$ is the local volume fraction of component $\gamma$ within phase $\alpha$ and $\rho^{\gamma}$ is the intrinsic density of component $\gamma$. However, assumption AB4 states that the volumes of sorbed

$$
\begin{aligned}
& \frac{\partial}{\partial t}\left((1-n)\left(1-\kappa_{s}^{b}-\kappa_{s}^{c}\right) \rho^{g}\right)=-\boldsymbol{\nabla} \cdot\left((1-n)\left(1-\kappa_{s}^{b}-\kappa_{s}^{c}\right)\left(\rho^{g} \boldsymbol{V}_{s}\right)\right)(5) \\
& \frac{\partial}{\partial t}\left((1-n) \mu^{b} B^{\prime} \rho^{b}\right)=-\nabla \cdot\left((1-n) \mu^{b} B^{\prime} \rho^{b} \boldsymbol{V}_{s}\right)-\Lambda_{s f}^{b}+\Omega_{s}^{b} \\
& \frac{\partial}{\partial t}\left((1-n) \frac{1}{\rho^{c}} m^{c} C^{\prime} \rho^{c}\right)=-\nabla \cdot\left((1-n) \frac{1}{\rho^{c}} m^{c} C^{\prime} \rho^{c} \boldsymbol{V}_{s}\right)+\Omega_{s}^{c} \\
& \frac{\partial}{\partial t}\left((1-n) m^{r} R^{\prime}\right)=-\nabla \cdot\left((1-n)\left(m^{r} R^{\prime} \mathbf{V}_{s}\right)\right)-\Lambda_{s f}^{r} \\
& \frac{\partial}{\partial t}\left((1-n) m^{p} P^{\prime}\right)=-\boldsymbol{\nabla} \cdot\left((1-n) m^{p} P^{\prime} \mathbf{V}_{s}\right)-\Lambda_{s f}^{p},
\end{aligned}
$$

where $n$ is the porosity; $\kappa_{s}^{b}$ and $\kappa_{s}^{c}$ are the local volume fraction of bacteria and calcite within the solid phase, respectively; $\rho^{g}, \rho^{b}$ and $\rho^{c}$ are the densities of the solid grains, the bacteria and the calcite $\left[\mathrm{kg} / \mathrm{m}^{3}\right]$, respectively; $\boldsymbol{V}_{\boldsymbol{s}}$ is the solid phase velocity; $\mu^{b}$ is the volume of a bacterial cell; $B^{\prime}$ is the number of bacterial cells per solid phase volume; $m^{c}, m^{r}$ and $m^{p}$ are the molar masses of calcite, urea/calcium and ammonium, respectively; $C^{\prime}, R^{\prime}$ and $P^{\prime}$ are the molar concentrations per solid phase volume of calcite, urea/calcium and ammonium, respectively; and $m^{r}$ is the molar mass of the chemical reactants.

Combining all of the mass balance equations of the solid phase components (Eqs. 5, 8, 9) yields the mass balance of the solid phase (according to the compositional approach). By considering assumption AB6, which is related to the negligible contribution of the net influx of the chemical species to the overall solid phase mass balance, the solid phase mass balance yields:

$\frac{\partial}{\partial t}\left((1-n) \rho_{s}\right)=-\nabla \cdot\left((1-n) \rho_{s} \boldsymbol{V}_{s}\right)-\Lambda_{s f}^{b}+\Omega_{s}^{b}+\Omega_{s}^{c}$,

where the solid phase density $\rho_{s}$ is defined as $\rho_{s}=\left(1-\mu^{b} B^{\prime}-\frac{1}{\rho^{c}} m^{c} C^{\prime}\right)+\mu^{b} B^{\prime} \rho^{b}+\frac{1}{\rho^{c}} m^{c} C^{\prime} \rho^{c}$.

Mass balance of the fluid phase. The fluid is assumed to be a perfectly miscible fluid (assumption AB5). Thus, the local volume fractions are not necessary when describing the volumetric composition of the phase. The suspended components are described in terms of the volumetric mass or the molarity of the fluid phase.

The mass balance for all of the fluid phase components yields the following equations for the pore water, the solute bacteria, the solute calcium/urea and the solute ammonium, respectively:

$$
\begin{aligned}
& \frac{\partial}{\partial t}\left(n \rho^{w}\right)=-\boldsymbol{\nabla} \cdot\left(n\left(\rho^{w} \boldsymbol{V}_{f}\right)\right) \\
& \frac{\partial}{\partial t}\left(n \mu^{b} B \rho^{b}\right)=-\boldsymbol{\nabla} \cdot\left(n\left(\mu^{b} B \rho^{b} \boldsymbol{V}_{f}+\boldsymbol{j}_{f}^{* b}\right)\right)-\Lambda_{f s}^{b}+\Omega_{f}^{b} \\
& \frac{\partial}{\partial t}\left(n m^{r} R\right)=-\boldsymbol{\nabla} \cdot\left(n\left(m^{r} R \boldsymbol{V}_{f}+\boldsymbol{j}_{f}^{* r}\right)\right)-\Lambda_{f s}^{r}+\Omega_{f}^{r} \\
& \frac{\partial}{\partial t}\left(n m^{p} P\right)=-\boldsymbol{\nabla} \cdot\left(n\left(m^{p} P \boldsymbol{V}_{f}+\boldsymbol{j}_{f}^{* p}\right)\right)-\Lambda_{f s}^{p}+\Omega_{f}^{p},
\end{aligned}
$$


where $B$ is the number of bacterial cells per fluid phase volume, and $R$ and $P$ are the molar concentrations per fluid phase volume of urea/calcium and ammonium, respectively.

The mass balance of the fluid phase composed of pore water, bacteria and chemical species, obtained by combining the mass balance equations of the fluid phase components (Eqs. (11)-(14)), neglecting the dispersive and the diffusive mass fluxes (assumption AB7), considering that the fluid volume remains constant over the entire domain upon reaction (assumption AB5) and neglecting the net influx of chemical species for the fluid phase (assumption AB6), is shown below:

$\frac{\partial}{\partial t}\left(n \rho_{f}\right)=-\nabla \cdot\left(n \rho_{f} \boldsymbol{V}_{f}\right)-\Lambda_{f s}^{b}+\Omega_{f}^{b}+\Omega_{f}^{r}+\Omega_{f}^{p}$,

where the fluid phase density $\rho_{f}$ is defined as $\rho_{f}=\rho^{w}+\vartheta^{b} B+m^{r} R+m^{p} P$.

\subsubsection{Momentum balance}

The momentum balance is expressed for the entire mixture by summing the phase momentum balance over the two phases according to the compositional approach. When dealing with either strain in porous medium or the transport of extensive quantities in a deformable porous medium, we need to refer to the stress in the porous medium as a whole [41]. This stress is obtained by writing the global momentum balance with the Terzaghi effective stress principle [18].

The macroscopical linear momentum of a phase is rewritten more concisely below according to assumptions $A B 3, A B 6, A B 7$ and AB9, with $E=m V^{m}, e=\rho \boldsymbol{V}^{m}, \boldsymbol{j}^{E U}=\boldsymbol{j}^{M m}=-\boldsymbol{\sigma}$ and $\Gamma^{E}=\boldsymbol{F}$ :

$0=\nabla \cdot \theta_{\alpha} \boldsymbol{\sigma}_{\alpha}-\Lambda_{\alpha \beta}^{M}+\Omega_{\alpha}^{M}$,

where $\boldsymbol{\sigma}_{\alpha}=-\boldsymbol{j}^{M m}=-\rho \boldsymbol{V}^{m}\left(\boldsymbol{V}^{M}-\boldsymbol{V}^{m}\right)$ is the diffusive flux of momentum $\left(\boldsymbol{\sigma}_{\alpha}\right.$ is the stress tensor of phase $\left.\alpha\right), \Lambda_{\alpha \beta}^{M}=-\overline{\overline{\boldsymbol{\sigma} \cdot \boldsymbol{v}^{\alpha}}} \bar{\Sigma}_{\alpha \beta}$ is the net influx of the linear momentum in phase $\alpha$, and $\Omega_{\alpha}^{M}=\theta_{\alpha} \overline{\rho \Gamma^{\mathrm{M}} \alpha}=\theta_{\alpha} \rho_{\alpha} \boldsymbol{F}_{\alpha}$ is the net rate of production of momentum in phase $\alpha$ ( $\boldsymbol{F}_{\alpha}$ are the body forces acting on the phase).

Momentum balance of the mixture. The momentum balance of the solid and the fluid phases yield:

$0=\nabla \cdot\left((1-n) \boldsymbol{\sigma}_{s}\right)-\Lambda_{s f}^{M}+(1-n) \rho_{s} \boldsymbol{F}_{s}$

$0=\nabla \cdot\left(n \boldsymbol{\sigma}_{f}\right)-\Lambda_{f s}^{M}+n \rho_{f} \boldsymbol{F}_{f}$,

where $\boldsymbol{\sigma}_{s}$ and $\boldsymbol{\sigma}_{f}$ are the stresses of the solid and the fluid phases, respectively, and $\boldsymbol{F}_{s}$ and $\boldsymbol{F}_{f}$ are the body forces acting on the solid and the fluid phases, respectively.

By summing the momentum balances of the solid and the fluid phases, the following momentum balance of the porous medium is obtained:

$\nabla \cdot \boldsymbol{\sigma}+\rho \boldsymbol{F}=0$,

where $\boldsymbol{\sigma}=(1-n) \boldsymbol{\sigma}_{s}+n \boldsymbol{\sigma}_{f}$ defines the volume-averaged stress or the total stress, and $\rho \boldsymbol{F}=(1-n) \rho_{s} \boldsymbol{F}_{s}+n \rho_{f} \boldsymbol{F}_{f}$ defines the total body force per unit volume of porous medium at a macroscopic point [12].

\subsection{Constitutive equations}

The constitutive conditions link the dependent variables and the unknowns. However, these additional equations depend on the specific nature of each phase and its components. This implies a two-way coupling within the field equations between the balance equations and the constitutive equations.

\subsubsection{Advective fluxes}

Because the injected bacteria and the chemical solution are assumed to be perfectly miscible with the pore water, the single fluid velocity governs all of their velocities. It is also assumed that the fluid pressure is not dependent on the concentrations. The relative fluid-solid velocity is assumed to be governed by the generalised Darcy's law (assumption AC1) shown below:

$n \boldsymbol{V}_{r}=n\left(\boldsymbol{V}_{f}-\boldsymbol{V}_{s}\right)=-K\left(\nabla p_{f}+\rho_{f} \mathbf{g}\right)$,

where $K$ is the kinematic permeability defined as $K=k / \mu$, in which $k$ is the intrinsic permeability and $\mu$ is the dynamic viscosity.

The intrinsic permeability $k$ is considered to be dependent on the porosity following the Kozeny-Karman formulation shown below [12]:

$k=C_{0} \frac{n^{a}}{(1-n)^{b}}$,

where $C_{0}, a$ and $b$ are material parameters.

\subsubsection{Non-advective fluxes}

Because both the diffusive and the dispersive fluxes are proportional to the density gradient, the two fluxes are typically combined to define one single flux, which is referred to as the flux of hydrodynamic dispersion [12]. This flux is expressed by the macroscopic Fick's law (assumption AC2) as follows in isotropic conditions according to $[16,12]$ :

$\boldsymbol{j}_{h f}^{\gamma}=\overline{\hat{\rho}^{\gamma} \widehat{\boldsymbol{V}}^{f}}+\boldsymbol{j}_{f}^{\gamma}=-\boldsymbol{D}_{f}^{\gamma} \cdot \nabla \rho_{f}^{\gamma}-\mathscr{D}^{* \gamma} \cdot \nabla \rho_{f}^{\gamma}=-\boldsymbol{D}_{h f}^{\gamma} \cdot \nabla \rho_{f}^{\gamma}$,

where $\boldsymbol{D}_{f}^{\gamma}$ is the coefficient of mechanical dispersion of component $\gamma$ expressed by $\boldsymbol{D}_{f}^{\gamma}=\left(a_{f L}^{\gamma}-a_{f T}^{\gamma}\right)\left(\boldsymbol{V}^{f} \cdot \boldsymbol{V}^{f}\right) /\left|\boldsymbol{V}^{f}\right|+a_{f T}^{\gamma}\left|\boldsymbol{V}^{f}\right| \boldsymbol{I}$ (where $a_{f L}^{\gamma}$ and $a_{f T}^{\gamma}$ are the longitudinal and the transversal dispersion coefficients, respectively), $\mathscr{D}^{* \gamma}$ is the coefficient of molecular diffusion of component $\gamma$ expressed by $\mathscr{D}^{* \gamma}=D^{\gamma} \boldsymbol{T}^{*}$ (where $D^{\gamma}$ is the molecular diffusion coefficient) and $\boldsymbol{D}_{h f}^{\gamma}=\boldsymbol{D}_{f}^{\gamma}+\mathscr{D}^{* \gamma}$ is the coefficient of hydrodynamic dispersion of component $\gamma$.

\subsubsection{Net influx}

Ref. [42] proposed that sufficiently fast and reversible reactions could be distinguished from insufficiently fast and/or irreversible reactions. For the first class of reactions, local equilibrium can be assumed mathematically (i.e., the reaction is assumed to reach equilibrium within the residence times characterising the transport regime). For the second class of reactions, a kinetic modelling approach is required to accurately describe the process.

Sorption/desorption of bacteria. In this model, the sorption of bacterial species is assumed to obey a first-order kinetic irreversible reaction (assumption AC3). It is assumed that the reversible adsorption is negligible with respect to the irreversible component. Under these assumptions, the rate of change of the bacterial concentration in either phase can be described as follows:

$\Lambda_{f s}^{b}=-\Lambda_{s f}^{b}=k_{a t t}^{b} n \vartheta^{b} B$,

where $k_{\text {att }}^{b}$ is the bacterial attachment rate.

Sorption/desorption of chemical species. The equilibrium approach can be considered satisfactory for modelling the adsorption of chemical species (assumption AC6) because there is a deliberately low injection rate during MICP to avoid flushing out the reacting species before the precipitation is effective. Considering that a precipitation reaction is typically slower than sorption, the latter can be considered instantaneous. The rate of chemical concentration change due to reversible sorption in either phase can be described as follows:

$$
\begin{aligned}
\Lambda_{f s}^{r} & =-\Lambda_{s f}^{r}=k_{a t t}^{r} n m^{r} R-k_{d e t}^{r}(1-n) m^{r} R^{\prime} ; \quad \Lambda_{f s}^{p}=-\Lambda_{s f}^{p} \\
& =k_{a t t}^{p} n m^{p} P-k_{d e t}^{p}(1-n) m^{p} P^{\prime},
\end{aligned}
$$


where $k_{a t t}^{r}$ and $k_{a t t}^{p}$ are the attachment rates of urea/calcium and ammonium, respectively, and $k_{\text {det }}^{r}$ and $k_{\text {det }}^{p}$ are the detachment rates of urea/calcium and ammonium, respectively.

Furthermore, considering that equilibrium between the sorbed and the solute chemical components is reached instantaneously at the time scale of the problem, the sorbed and the solute chemical species components can be linked together through the partitioning coefficients shown below:

$R^{\prime}=K_{d}^{r} \frac{n}{(1-n)} R ; \quad P^{\prime}=K_{d}^{p} \frac{n}{(1-n)} P$,

where $K_{d}^{r}=k_{a t t}^{r} / k_{d e t}^{r}$ and $K_{d}^{p}=k_{\text {att }}^{p} / k_{\text {det }}^{p}$ are the partitioning coefficients of urea/calcium and ammonium, respectively.

\subsubsection{Net production rate}

Decay of bacteria. The net production rate of bacteria results from the decay or the degradation phenomena of bacteria as no growth is considered in the system (assumptions AC4 and AC5). The first-order, irreversible reaction of bacterial decay according to [22] is shown below:

$\Omega_{s}^{b}=-k_{d}^{b}(1-n) \vartheta^{b} B^{\prime} ; \quad \Omega_{f}^{b}=-k_{d}^{b} n \vartheta^{b} B$,

where $k_{d}^{b}$ is the bacterial decay rate in both solid and the fluid phases.

Biologically catalysed chemical reaction. The chemical equilibrium configuration of the system is parameterised through an overall reaction progress variable or rate (assumption AC7). As described in Section 2.1, the overall biogrout reaction is actually composed of several chemical processes (hydrolysis, acid-base equilibria and precipitation), and precipitation depends on at least two processes (nucleation and crystal growth), all of which obey different kinetics. However, van Paassen [7] proposed a simple single reaction approach which was demonstrated to yield similar accuracy of the predicted concentration of the main compounds with respect to experimental findings as more complex models which considers acid-base equilibria and precipitation kinetics. In such an approach, the overall biogrout reaction can be modelled as a first-order irreversible kinetic reaction. As shown below, the urea/calcium and the ammonium in the fluid phase (assumption AC8) and the calcite mass balance equations are influenced by the overall biogrout reaction:

$\Omega_{s}^{c}=k_{\text {rea }} n m^{c} ; \quad \Omega_{f}^{r}=-k_{\text {rea }} n m^{r} ; \quad \Omega_{f}^{p}=2 k_{\text {rea }} n m^{p}$,

where $k_{\text {rea }}$ is the overall reaction rate defined as the number of moles reacting per unit volume of the fluid phase per unit second, i.e. $\left[\mathrm{mol} / \mathrm{m}^{3} . \mathrm{s}\right]$ (the adsorption, the desorption and the decay rates are defined per unit time $\left.\left[\mathrm{s}^{-1}\right]\right)$.

The reaction rate $k_{\text {rea }}$ is likely to decrease throughout the process due to e.g. consumption of reactants, decay of bacteria, and encapsulation of bacteria in calcite crystals. The urea depletion effect follows Michaelis-Menten kinetics as proposed in [7]. The expression shown below is considered based on the experimental observations of $[7,11]$ assuming a constant surface area. The decreasing activity of the bacteria over time is represented by the latter term of the following empirical equation:

$k_{\text {rea }}=U \frac{R}{K^{m}+R} \exp \left(-\frac{t}{t_{d}}\right)$,

where $U$ is the initial maximum rate or the urease activity; $K^{m}$ is the half saturation constant (i.e., the concentration at which the rate is reduced by 50\%); $t$ and $t_{d}$ are the time and the exponential time constant, respectively, at which the urease activity has been reduced by a factor $e=2.71828$

Both the attached bacteria $B^{\prime}$ and the suspended bacteria $B$ are sources of urease activity (assumption AC9). The initial specific urease activity is an experimentally determined parameter for the injected bacteria $u_{s p}$. $U$ is the initial urease activity, which is composed of the initial specific urease activity and the cell density as shown below:

$U=\frac{(1-n)}{n} u_{s p} B^{\prime}+u_{s p} B$

\subsubsection{Stress-strain relationship}

The elastic mechanical constitutive model will be presented with the stress invariants mean effective stress $p^{\prime}=\frac{1}{3}\left(\sigma_{x}^{\prime}+\sigma_{y}^{\prime}+\sigma_{z}^{\prime}\right)$ and deviatoric stress $q=\sigma_{x}^{\prime}-\sigma_{z}^{\prime}$. The associated strains are the volumetric strain $\varepsilon_{v}=\left(\varepsilon_{x}+\varepsilon_{y}+\varepsilon_{z}\right)$ and the deviatoric strain $\varepsilon_{d}=\frac{2}{3}\left(\varepsilon_{x}-\varepsilon_{z}\right)$. The adopted stress-strain relationship is an elastic one. An elaborate bio-chemo-mechanical constitutive model is proposed in Fauriel and Laloui [13] and could replace the elastic model for a better description of the mechanical response.

The volumetric $d \varepsilon_{v}$ and the deviatoric $d \varepsilon_{d}$ components of the elastic strain increment are given by:

$d \varepsilon_{v}^{e}=\frac{d p^{\prime}}{K} ; \quad d \varepsilon_{d}^{e}=\frac{d q}{3 G}$,

where $K$ is the bulk elastic modulus and $G$ is the shear elastic modulus.

The relationships given in incremental volumetric and deviatoric forms can also be given in a matricial incremental form, which relates the stress tensor increment to the strain rate tensor, as shown below:

$d \boldsymbol{\sigma}^{\prime}=\boldsymbol{D}^{e}:\left(d \boldsymbol{\varepsilon}^{e}-d \boldsymbol{\varepsilon}_{0}^{e}\right)$,

where $\boldsymbol{D}^{e}$ is the elastic tensor.

The non-linear bulk and shear elastic moduli are given by:

$K_{C_{0}}=K_{\text {ref }}\left(\frac{p^{\prime}}{p_{r e f}}\right)^{n^{e}} ; \quad G_{C_{0}}=G_{r e f}\left(\frac{p^{\prime}}{p_{r e f}}\right)^{n^{e}}$

where $K_{\text {ref }}$ is the bulk elastic modulus at a reference pressure, $G_{r e f}$ is the shear elastic modulus at a reference pressure $p_{\text {ref }}$ and $n^{e}$ is a material constant. The two elastic moduli are linked together through Poisson's ratio $v ; G=\frac{3(1-2 v)}{2(1+v)} K$.

The elastic moduli are affected by both the confining pressure and the bacterially catalysed precipitation of calcite. Al Qabany et al. [8] established a linear relationship between the calcite content and the shear wave velocity. The researchers determined a strong correlation between the two variables and proposed the general empirical correlation shown below:

$v_{S}=152+9.7 \widehat{C}^{\prime}=152+9.7 m^{c} C^{\prime}$,

where $v_{s}$ is the shear wave velocity $[\mathrm{m} / \mathrm{s}]$ and $\widehat{C}^{\prime}$ the mass of calcite per unit volume of the solid phase $\left[\mathrm{kg} / \mathrm{m}^{3}\right]$.

In this model, the increase in shear wave velocity due to calcite precipitation will be taken from the linear portion of the correlation of Al Qabany et al. [8]. As shown below, the shear wave velocity increase can be translated into a change in the shear elastic modulus through its dependence on the shear wave velocity $G=\rho_{d} v_{s}^{2}$, where $\rho_{d}$ is the soil density, and the bulk elastic modulus can be estimated by assuming that the Poisson's ratio is constant upon cementation:

$G_{C}=\left(1+\frac{9.7}{152} m^{c} C^{\prime}\right)^{2} G_{C_{0}} ; \quad K_{C}=\left(1+\frac{9.7}{152} m^{c} C^{\prime}\right)^{2} K_{C_{0}}$,

\subsubsection{Fluid phase state equation}

The fluid phase density is dependent upon its composition according to the relationship below: 
$\rho_{f}=\rho^{w}+\vartheta^{b} B+m^{r} R+m^{p} P$

However, the water density is dependent on the pressure and the temperature. Assuming a barotropic fluid (assumption AC10), the fluid phase state equation can be expressed as: $\rho_{f}=\rho_{f}\left(p_{f}, B, R, P\right)$.

Differentiating the above equation yields:

$$
\begin{aligned}
d \rho_{f} & =\frac{\partial \rho_{f}}{\partial p_{f \mid B, R, P}} d p_{f}+\frac{\partial \rho_{f}}{\partial B_{\mid p_{f}, R, P}} d B+\frac{\partial \rho_{f}}{\partial R_{\mid p_{f}, B, P}} d R+\frac{\partial \rho_{f}}{\partial P_{\mid p_{f}, B, R}} d P \\
& =\left(\beta_{p_{\gamma}} d p_{f}+\beta^{b} d B+\beta^{r} d R+\beta^{p} d P\right) \rho_{f},
\end{aligned}
$$

where $\beta^{f}$ is the coefficient of compressibility of the fluid phase at constant concentrations, and $\beta^{b}, \beta^{r}$ and $\beta^{p}$ are the coefficients of concentration of the fluid phase at a constant fluid pressure defining the variation of the fluid phase density due to varying concentrations.

The effect of the composition on the fluid viscosity is assumed to be negligible.

\subsection{Field equations}

The field equations are obtained by combining the mass balance equations and introducing the related constitutive equations. The balance equations can only be solved if the related constitutive equations are specified. Conversely, the coefficients of the constitutive equations may depend on the primary unknowns. Thus, there is a two-way coupling between the balance equations and the constitutive equations.

\subsubsection{Flow equation}

Combining the mass balance of the fluid phase (Eq. (15)) with the Eqs. (23), (26) and (27) yields:

$\frac{\partial}{\partial t}\left(n \rho_{f}\right)=-\nabla \cdot\left(n \rho_{f} \boldsymbol{V}_{f}\right)-k_{\text {att }}^{b} n \vartheta^{b} B-k_{d} n \vartheta^{b} B-k_{\text {rea }} n m^{r}$

$$
+2 k_{\text {rea }} n m^{p} \text {. }
$$

The porosity variation can be eliminated from the above equation by considering the solid phase mass balance. In this manner, a coupling between the solid deformation and the bio-chemical processes and the flow is introduced. The mass balance of the solid phase (Eq. (10)) completed by the relevant constitutive relations expressed by Eqs. (23), (26) and (27), yields:

$$
\begin{aligned}
\frac{\partial}{\partial t}\left((1-n) \rho_{s}\right)= & -\boldsymbol{\nabla} \cdot\left((1-n) \rho_{s} \boldsymbol{V}_{s}\right)+k_{a t t}^{b} n \vartheta^{b} B-k_{d}^{b}(1 \\
& -n) \vartheta^{b} B^{\prime}+k_{\text {rea }} n m^{c} .
\end{aligned}
$$

The changes in porosity are due to the solid deformation and changes in the solid phase density and the volume upon filtration of bacteria and calcite onto the solid grains. In the above equation, all of the contributions can be clearly identified.

By considering that porosity does not vary in space in the REV the porosity variation in time obtained by developing the mass balance of the solid phase (Eq. (39)) can be introduced into the developed fluid phase mass balance (Eq. (38)), along with Darcy's law and the state equations of the phase densities. The relationship $\boldsymbol{\nabla} \cdot \boldsymbol{V}_{s}=\boldsymbol{m}^{T} \mathbf{L} \partial \boldsymbol{u}_{s} / \partial t$ is also considered:

$$
\begin{array}{rl}
\boldsymbol{m}^{T} & \mathbf{L} \frac{\partial \boldsymbol{u}_{s}}{\partial t}-\nabla \cdot\left(K\left(\nabla p_{f}+\rho_{f} \boldsymbol{g}\right)\right)+n \beta_{p_{f}} \frac{\partial p_{f}}{\partial t} \\
= & -n \beta_{\gamma} \frac{\partial A^{\gamma}}{\partial t}(1-n)-\frac{1}{\rho_{s}} \frac{\partial \rho_{s}}{\partial B^{\prime}} \frac{\partial B^{\prime}}{\partial t}-(1-n) \frac{1}{\rho_{s}} \frac{\partial \rho_{s}}{\partial C^{\prime}} \frac{\partial C^{\prime}}{\partial t} \\
& -\left(\frac{1}{\rho_{f}}-\frac{1}{\rho_{s}}\right) k_{a t t}^{b} n \vartheta^{b} B-\left(\frac{1}{\rho_{f}} n B+\frac{1}{\rho_{s}}(1-n) B^{\prime}\right) k_{d}^{b} \vartheta^{b} \\
& -\left(\frac{1}{\rho_{f}}\left(m^{r}-2 m^{p}\right)-\frac{1}{\rho_{s}} m^{c}\right) k_{\text {rea }} n
\end{array}
$$

where

$$
\boldsymbol{L}^{T}=\left[\begin{array}{cccccc}
\frac{\partial}{\partial x} & 0 & 0 & 0 & \frac{\partial}{\partial z} & \frac{\partial}{\partial y} \\
0 & \frac{\partial}{\partial y} & 0 & \frac{\partial}{\partial z} & 0 & \frac{\partial}{\partial x} \\
0 & 0 & \frac{\partial}{\partial z} & \frac{\partial}{\partial y} & \frac{\partial}{\partial x} & 0
\end{array}\right] .
$$

\subsubsection{Equilibrium equation}

According to the effective stress principle of Terzaghi [43], the effective stress $\boldsymbol{\sigma}^{\prime}$ is defined as the sum of the fluid pressure and the stress in the solid phase and can be expressed as:

$$
\boldsymbol{\sigma}^{\prime}=(1-n)\left(\boldsymbol{\sigma}_{s}+\boldsymbol{m} p_{f}\right)=(1-n) \boldsymbol{\sigma}_{s}+(1-n) \boldsymbol{m} p_{f},
$$

where $p_{f}$ is the fluid phase pressure, $\boldsymbol{m}=[1,1,1,0,0,0]^{T}$ and $\boldsymbol{\sigma}^{\prime}$ is the effective stress tensor.

The volume-averaged stress or the total stress as defined in Section 4.1.2 can be rewritten using the above effective stress definition as $\boldsymbol{\sigma}=(1-n) \boldsymbol{\sigma}_{s}-n \boldsymbol{m} p_{f}=\boldsymbol{\sigma}^{\prime}-\boldsymbol{m} p_{f}$. By combining Eq. (19) and the expression for total stress and neglecting the external forces in the expression for the total body force $(\boldsymbol{F}=\boldsymbol{g}+\boldsymbol{t})$, the following expression is obtained using the differential operator $\boldsymbol{L}$ given for strains for the divergence of the array of stresses:

$\boldsymbol{L}^{T}\left(\boldsymbol{\sigma}^{\prime}-\boldsymbol{m} p_{f}\right)+\rho \mathbf{g}=0$.

\subsubsection{Transport equations}

The following equations are obtained for the mass balance of the attached components of the bacteria and calcite by introducing the constitutive expressions of the net influx (Eq. (23)) and the net production rate (Eqs. (26) and (27)) into the component mass conservation (Eqs. (6) and (7)):

$$
\begin{aligned}
\frac{\partial B^{\prime}}{\partial t}= & -\nabla\left(B^{\prime}\right) \cdot \boldsymbol{V}_{s}-\frac{B^{\prime}}{(1-n)} \nabla \cdot\left((1-n) \boldsymbol{V}_{s}\right)+\frac{B^{\prime}}{(1-n)} \frac{\partial n}{\partial t} \\
& +k_{\text {att }}^{b} \frac{n}{(1-n)} B-k_{d}^{b} B^{\prime}
\end{aligned}
$$

$$
\begin{aligned}
\frac{\partial C^{\prime}}{\partial t}= & -\nabla\left(C^{\prime}\right) \cdot \boldsymbol{V}_{s}-\frac{C^{\prime}}{(1-n)} \nabla \cdot\left((1-n) \mathbf{V}_{s}\right)+\frac{C^{\prime}}{(1-n)} \frac{\partial n}{\partial t} \\
& +k_{\text {rea }} n .
\end{aligned}
$$

Assuming that the solid skeleton deformation is such that $\left|\partial B^{\prime} / \partial t\right| \gg\left|\boldsymbol{\nabla}\left(B^{\prime}\right) \cdot \boldsymbol{V}_{s}\right|$ and $|\partial C / \partial t| \gg\left|\nabla(C) \cdot V_{s}\right|$ and introducing the expression for the variation in the porosity (Eq. (9)) and Darcy's law (Eq. (20)), the following transport equations are obtained:

$$
\begin{aligned}
\frac{\partial B^{\prime}}{\partial t}= & {\left[\frac{1}{\rho_{s}} \frac{d_{s} \rho_{s}}{d t}+\frac{1}{\rho_{s}}\left(-k_{a t t}^{b} \frac{n}{(1-n)} \vartheta^{b} B+k_{d} \vartheta^{b} B^{\prime}-k_{\text {rea }} \frac{n}{(1-n)} m^{c}\right)\right] B^{\prime} } \\
& +k_{a t t}^{b} \frac{n}{(1-n)} B-k_{d}^{b} B^{\prime}
\end{aligned}
$$

$$
\begin{aligned}
\frac{\partial C^{\prime}}{\partial t}= & {\left[\frac{1}{\rho_{s}} \frac{d_{s} \rho_{s}}{d t}+\frac{1}{\rho_{s}}\left(-k_{\text {att }}^{b} \frac{n}{(1-n)} \vartheta^{b} B+k_{d} \vartheta^{b} B^{\prime}-k_{\text {rea }} \frac{n}{(1-n)} m^{c}\right)\right] C^{\prime} } \\
& +k_{\text {rea }} n .
\end{aligned}
$$

The term in brackets is the porosity variation effect, which will induce a change in the sorbed concentrations as they are defined per unit volume of the solid phase. The other terms relate to the filtration and are also present in the flow equation; these terms express the effective concentration changes in terms of the species mass variations. 
Combining the mass balance equation of the suspended bacteria (Eq. (12)) with the relevant constitutive expressions (Eqs. (23) and (27)) yields the following equation:

$$
\begin{aligned}
\frac{\partial B}{\partial t}= & -\nabla(B) \cdot \boldsymbol{V}_{s}-\frac{1}{n} B \nabla \cdot\left(n \boldsymbol{V}_{s}\right)-\frac{1}{n} \nabla \cdot\left(n B \boldsymbol{V}_{r}-n \boldsymbol{D}_{h f}^{b} \nabla B\right) \\
& -\frac{B}{n} \frac{\partial n}{\partial t}-k_{a t t}^{b} B-k_{d}^{b} B .
\end{aligned}
$$

Because the solid deformation is such that $|\partial B / \partial t| \gg\left|\nabla(B) \cdot V_{s}\right|$ and $\left|\boldsymbol{\nabla} \cdot\left(n B \boldsymbol{V}_{r}\right)\right| \gg\left|B \boldsymbol{\nabla} \cdot\left(n \boldsymbol{V}_{s}\right)\right|$, introducing both the expression for the variation of porosity (Eq. (39)) and Darcy's law (Eq. (20)) into the previous expression yields the following transport equation for the bacteria within the fluid phase:

$$
\begin{aligned}
\frac{\partial B}{\partial t} & =-\frac{1}{n} \nabla \cdot\left(-B K\left(\nabla p^{f}+\rho^{f} g\right)-n \boldsymbol{D}_{h f}^{b} \nabla B\right) \\
& -\left[\frac{1}{n} \nabla \cdot\left((1-n) \boldsymbol{V}_{s}\right)+\frac{(1-n)}{n} \frac{1}{\rho_{s}} \frac{d_{s} \rho_{s}}{d t}\right. \\
& \left.+\frac{1}{\rho_{s}}\left(-k_{a t t}^{b} \vartheta^{b} B+k_{d} \frac{(1-n)}{n} \vartheta^{b} B^{\prime}-k_{\text {rea }} m^{c}\right)\right] B-k_{a t t}^{b} B-k_{d}^{b} B .
\end{aligned}
$$

With the assumption of a linear equilibrium isotherm, the only unknown is the concentration of the solute component. The exchange terms among components of these species are cancelled out from the overall mass balance equation of the species by combining the component mass balance equations and introducing the constitutive expressions. For urea/calcium (Eqs. (8) and (13)) and ammonium (Eqs. (9) and (14)), the species mass balance yields:

$$
\begin{aligned}
\left(1+K_{d}^{r}\right) \frac{\partial R}{\partial t}= & -\left(1+K_{d}^{r}\right) \nabla R \cdot \boldsymbol{V}_{s}-\left(1+K_{d}^{r}\right) R \boldsymbol{\nabla} \cdot\left(n \boldsymbol{V}_{s}\right) \\
& -\frac{1}{n} \boldsymbol{\nabla} \cdot\left(-R K\left(\nabla p^{f}+\rho^{f} \mathbf{g}\right)-n \boldsymbol{D}_{h f}^{r} \boldsymbol{\nabla} R\right) \\
& -\left(1+K_{d}^{r}\right) \frac{R}{n} \frac{\partial n}{\partial t}-k_{\text {rea }},
\end{aligned}
$$

$$
\begin{aligned}
\left(1+K_{d}^{p}\right) \frac{\partial P}{\partial t}= & -\left(1+K_{d}^{p}\right) \nabla P \cdot \boldsymbol{V}_{s}-\left(1+K_{d}^{p}\right) P \nabla \cdot\left(n \boldsymbol{V}_{s}\right) \\
& -\frac{1}{n} \boldsymbol{\nabla} \cdot\left(-P K\left(\nabla p^{f}+\rho^{f} \mathbf{g}\right)-n \boldsymbol{D}_{h f}^{p} \boldsymbol{\nabla} P\right) \\
& -\left(1+K_{d}^{p}\right) \frac{P}{n} \frac{\partial n}{\partial t}+2 k_{\text {rea }} .
\end{aligned}
$$

Considering $|\partial \mathrm{R} / \partial t| \gg\left|\nabla R \cdot \boldsymbol{V}_{s}\right|,|\partial \mathrm{P} / \partial t| \gg\left|\nabla P \cdot \boldsymbol{V}_{s}\right|,\left|\boldsymbol{\nabla} \cdot\left(n R \boldsymbol{V}_{r}\right)\right|$ $\gg\left|\left(1+K_{d}^{r}\right) R \nabla \cdot\left(n \boldsymbol{V}_{s}\right)\right|$ and $\left|\boldsymbol{\nabla} \cdot\left(n P \boldsymbol{V}_{r}\right)\right| \gg\left|\left(1+K_{d}^{p}\right) P \boldsymbol{\nabla} \cdot\left(n \boldsymbol{V}_{s}\right)\right|$ and Eqs. (39) and (20), the final transport equations for urea/calcium and ammonium are:

$$
\begin{aligned}
\left(1+K_{d}^{r}\right) \frac{\partial R}{\partial t}= & -\frac{1}{n} \nabla \cdot\left(-R K\left(\nabla p^{f}+\rho^{f} \mathbf{g}\right)-n \boldsymbol{D}_{h f}^{r} \nabla R\right)-\left[\frac{1}{n} \nabla \cdot((1\right. \\
& \left.-n) \boldsymbol{V}_{s}\right)+\frac{(1-n)}{n} \frac{1}{\rho_{s}} \frac{d_{s} \rho_{s}}{d t} \\
& \left.+\frac{1}{\rho_{s}}\left(-k_{\text {att }}^{b} \vartheta^{b} B+k_{d} \frac{(1-n)}{n} \vartheta^{b} B^{\prime}-k_{\text {rea }} m^{c}\right)\right](1 \\
& \left.+K_{d}^{r}\right) R-k_{\text {rea }}, \\
\left(1+K_{d}^{p}\right) \frac{\partial P}{\partial t}= & -\frac{1}{n} \nabla \cdot\left(-P K\left(\nabla p^{f}+\rho^{f} \mathbf{g}\right)-n \boldsymbol{D}_{h f}^{p} \nabla P\right)-\left[\frac{1}{n} \boldsymbol{\nabla}\right. \\
& \cdot\left((1-n) \mathbf{V}_{s}\right)+\frac{(1-n)}{n} \frac{1}{\rho_{s}} \frac{d_{s} \rho_{s}}{d t} \\
& \left.+\frac{1}{\rho_{s}}\left(-k_{\text {att }}^{b} \vartheta^{b} B+k_{d} \frac{(1-n)}{n} \vartheta^{b} B^{\prime}-k_{\text {rea }} m^{c}\right)\right](1 \\
& \left.+K_{d}^{p}\right) P+2 k_{\text {rea }} .
\end{aligned}
$$

\subsubsection{Final formulation}

Under the previous considerations, the system of field equations composed of Eqs. 40, 42, 45, 46, 48, 51 and 52 is written in terms of the seven primary unknowns: the pore pressure $\left(p_{f}\right)$, the solid displacement tensor $\left(\boldsymbol{u}_{s}\right)$, the adsorbed bacteria concentration $\left(B^{\prime}\right)$, the calcite concentration $\left(C^{\prime}\right)$, the suspended bacteria concentration $(B)$, the suspended urea/calcium concentration $(R)$ and the suspended ammonium concentration $(P)$. This system represents the coupled bio-chemo-hydro-mechanical formulation of the two-phase model for MICP-treated porous media.

\section{Numerical integration}

In the final system, the conventional hydro-mechanical coupling is supplemented by bio-chemo-mechanical, bio-chemohydraulic and bio-chemical couplings. The finite element code used to implement the equations is LAGAMINE, which was developed at the University of Liège $[44,45]$. Elements treating the conventional hydro-mechanical couplings (MWAT) and elements dealing with one-species non-reactive pollutant transport (ADVEC) are already implemented in LAGAMINE. However, the coupling between the two existing element types is a one-way coupling as the porosity and the flow are unaffected by the pollutant transport. The challenges to face in the integration of the BCHM model are as follows:

- The problem is highly coupled.

- The involved couplings are mainly two-way couplings.

- Additional degrees of freedom are needed to accommodate multispecies transport.

\subsection{Couplings involved in the problem}

Two-way couplings imply that the time response of the subsystems must be evaluated concurrently. Two-way couplings exist between the four subsystems (the flow problem $\mathrm{H}$, the mechanical problem $\mathrm{M}$, the biological transport problem $\mathrm{B}$ and the chemical transport problem $\mathrm{C}$ ) which have been pragmatically defined in the mathematical model. The couplings between the primary variables result in the definitions of new subsystems that will be the basis of the numerical treatment.

The first subsystem is the hydro-mechanical HM subsystem in which the couplings are assumed to be strong. Thus, the subsystem HM should be treated with a monolithic approach (this will not be further discussed in this paper, but details can be found in [44,45]). The second subsystem is the bio-chemical BC subsystem in which

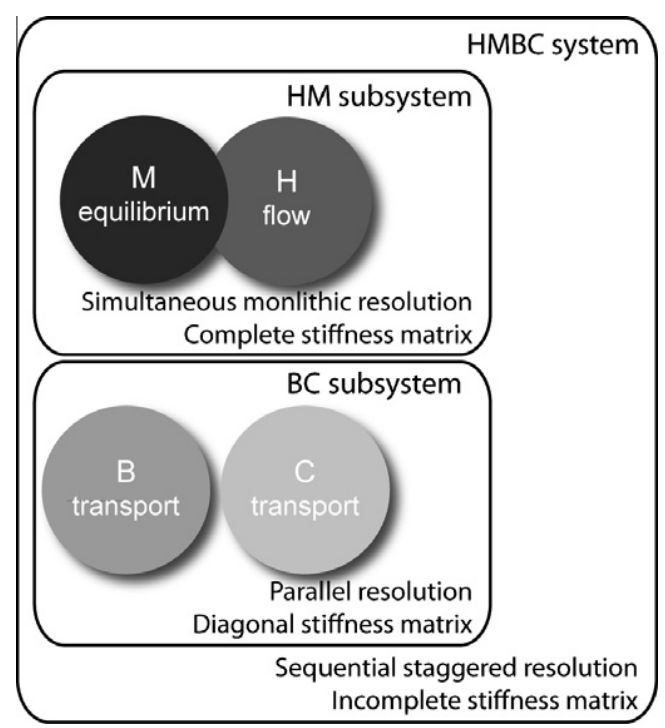

Fig. 3. Numerical couplings. 
(a)

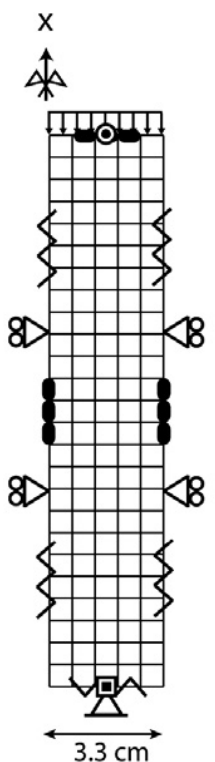

(b)

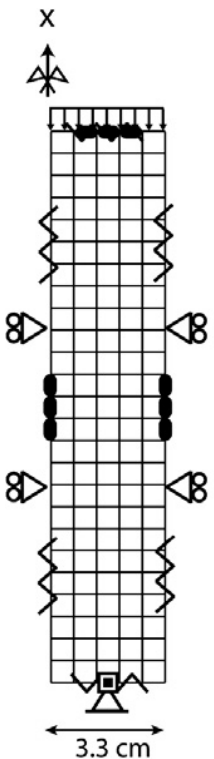

(c)

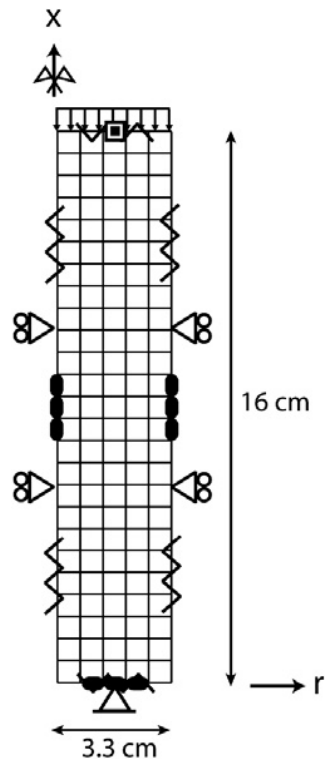

Dirichlet's type boundary conditions

$\Delta$ Imposed solid displacement $\Delta \frac{\Delta}{\Delta}$ perpendicularly

ㅁ Imposed fluid pressure

- Imposed biological/chemical concentration

Neumann's type boundary conditions

IIII Imposed mechanical stress

- Imposed advective fluid flux

M Imposed hydrodynamic dispersive biological/chemical flux

Fig. 4. Schematic representation of the modelled case: a. the hydro-bacterial and the hydro-chemical injections and the mechanical loading phases, b. the rinsing phase and c. the setting phases.

the equations are decoupled. The transport equations will therefore be solved sequentially within subsystem BC. Finally, the two subsystems will be solved sequentially in a staggered approach. The global resolution approach is illustrated in Fig. 3.

\subsection{Spatial and temporal discretisation}

The finite element formulation of the problem is obtained by multiplying the strong form of the field equations by a weighting function $\boldsymbol{W}_{j}$ and integrating over the entire domain. The unknowns of each weighted equation are spatially and temporally discretised

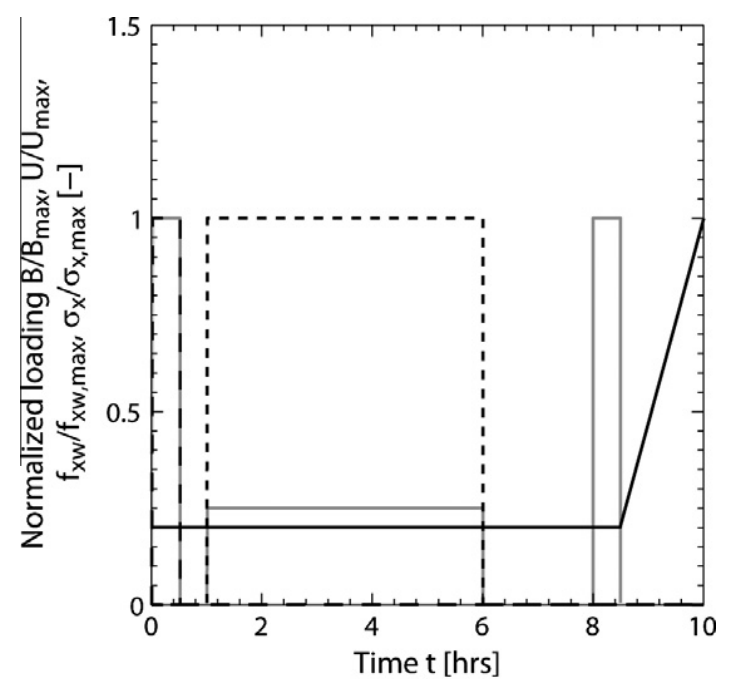

$$
\begin{aligned}
& - \text { Mechanical stress, } \sigma_{\mathrm{x}, \max }=500 \mathrm{kPa} \\
& - \text { Fluid flux, } \mathrm{f}_{\mathrm{xw} \text {,max }}=8 \mathrm{ml} / \mathrm{min} \\
& -- \text { Bacterial concentration, } \mathrm{B}_{\max }=3 \mathrm{OD} \\
& -- \text { Chemical concentration, } \mathrm{U}_{\max }=0.5 \mathrm{M}
\end{aligned}
$$

Fig. 5. Loading sequence.

by means of shape functions $\boldsymbol{N}_{j}^{x}$, temporal functions $\boldsymbol{N}_{j}^{t}$ and the values of the unknowns at the nodes. In the standard Bubnov-Galerkin methods, the original shape functions are used as weighting (i.e., $\boldsymbol{W}_{j}^{x}=\boldsymbol{N}_{j}^{x}$ ). This method is applied for the flow and the equilibrium equations. Since the late seventies, an alternative family of methods has been developed to overcome the problem of spatial instabilities encountered in advection-dominated advection-diffusion problems. These methods, referred to as the Petrov-Galerkin methods, are based on the use of specific weighting functions $\boldsymbol{W}_{j}=\boldsymbol{N}_{j}^{x}+\boldsymbol{F}_{j}$, which add a discontinuous upwind function $\boldsymbol{F}_{j}$ to the continuous shape functions $\boldsymbol{N}_{j}^{x}$ giving more importance to the neighbouring elements that are upstream with respect to the advection velocity. This method is applied to the transport equations of subsystem BC. The weak form of the problem obtained is an approximation to the integral statement of the problem and results in a set of simultaneous algebraic equations for the unknowns. This final integral system can be transformed into a sum by means of the Gauss quadrature, which approximates the defi-

\begin{tabular}{|c|c|c|}
\hline $\begin{array}{l}\text { Mechanical parameters } \\
K_{r e f}, G_{r e f}, p_{r e f}, n^{e}, \rho^{g}\end{array}$ & {$[\mathrm{MPa}],[\mathrm{MPa}],[\mathrm{MPa}],[-],\left[\mathrm{kg} / \mathrm{m}^{3}\right]$} & $100,75,1,1,2600$ \\
\hline $\begin{array}{l}\text { Hydraulic parameters } \\
n_{0}, \rho^{w}, \mu^{w}, 1 / \chi_{f} \\
k_{0}, a, b\end{array}$ & $\begin{array}{l}{[-],\left[\mathrm{kg} / \mathrm{m}^{3}\right],[\mathrm{Pas}],[\mathrm{MPa}]} \\
{\left[\mathrm{m}^{2}\right],[-],[-]}\end{array}$ & $\begin{array}{l}0.4,1000,1 \times 10^{-3}, 5 \times 10^{-4} \\
2 \times 10^{-12}, 3,2\end{array}$ \\
\hline $\begin{array}{l}\text { Biological parameters } \\
u_{s p}, t_{d}, \beta^{b}, \mu^{b} \\
a_{f T}^{b}, a_{f L}^{b}, \mathscr{D}^{* b} \\
k_{a t t}^{b}, k_{d}^{b}\end{array}$ & $\begin{array}{l}{\left[\mathrm{kmol} / \mathrm{m}^{3} \mathrm{sOD}\right],[\mathrm{s}],\left[\mathrm{kg} / \mathrm{m}^{3} \mathrm{OD}\right],\left[\mathrm{m}^{3} / \mathrm{OD}\right]} \\
{[\mathrm{m}],[\mathrm{m}],\left[\mathrm{m}^{2} / \mathrm{s}\right]} \\
{\left[\mathrm{s}^{-1}\right],\left[\mathrm{s}^{-1}\right]}\end{array}$ & $\begin{array}{l}2 \times 10^{-5}, 28,800,0,0 \\
1 \times 10^{-3}, 2 \times 10^{-3}, 2 \times 10^{-9} \\
3 \times 10^{-4}, 0\end{array}$ \\
\hline $\begin{array}{l}\text { Chemical parameters } \\
K^{m}, \beta^{r}, \beta^{p} \\
\rho^{c}, m^{c}, m^{r}, m^{p} \\
a_{f T}^{r}, a_{f T}^{p}, a_{f L}^{r}, a_{f L}^{p}, \mathscr{D}^{* r}, \mathscr{D}^{* p}, \\
K_{d}^{r}, K_{d}^{r}\end{array}$ & $\begin{array}{l}{[-],\left[\mathrm{kg} / \mathrm{m}^{3} \mathrm{~mol}\right],\left[\mathrm{kg} / \mathrm{m}^{3} \mathrm{~mol}\right]} \\
{\left[\mathrm{kg} / \mathrm{m}^{3}\right],[\mathrm{g} / \mathrm{mol}],\left[\mathrm{g} / \mathrm{mol}^{2},[\mathrm{~g} / \mathrm{mol}]\right.} \\
{[\mathrm{m}],[\mathrm{m}],[\mathrm{m}],[\mathrm{m}],\left[\mathrm{m}^{2} / \mathrm{s}\right],\left[\mathrm{m}^{2} / \mathrm{s}\right]} \\
{[-],[-]}\end{array}$ & $\begin{array}{l}0.01,0,0 \\
1400,100,118,18 \\
1 \times 10^{-3}, 1 \times 10^{-3}, 2 \times 10^{-3}, 2 \times 10^{-3}, 2 \times 10^{-9}, 2 \times 10^{-9} \\
1,1\end{array}$ \\
\hline
\end{tabular}
nite integral of a function stated as a weighted sum of the function

Table 1

Material parameters used in the modelling.

Note: $\mathrm{m}^{r}$ is taken as the sum of the masses of $1 \mathrm{~mol}$ of urea, $1 \mathrm{~mol}$ of calcium and $2 \mathrm{~mol}$ of water. The bacterial concentrations are expressed in the unit OD (the optical density measured at a wavelength of $600 \mu \mathrm{m}$ ). The same unit is used in the solid phase even though it has no physical meaning. 

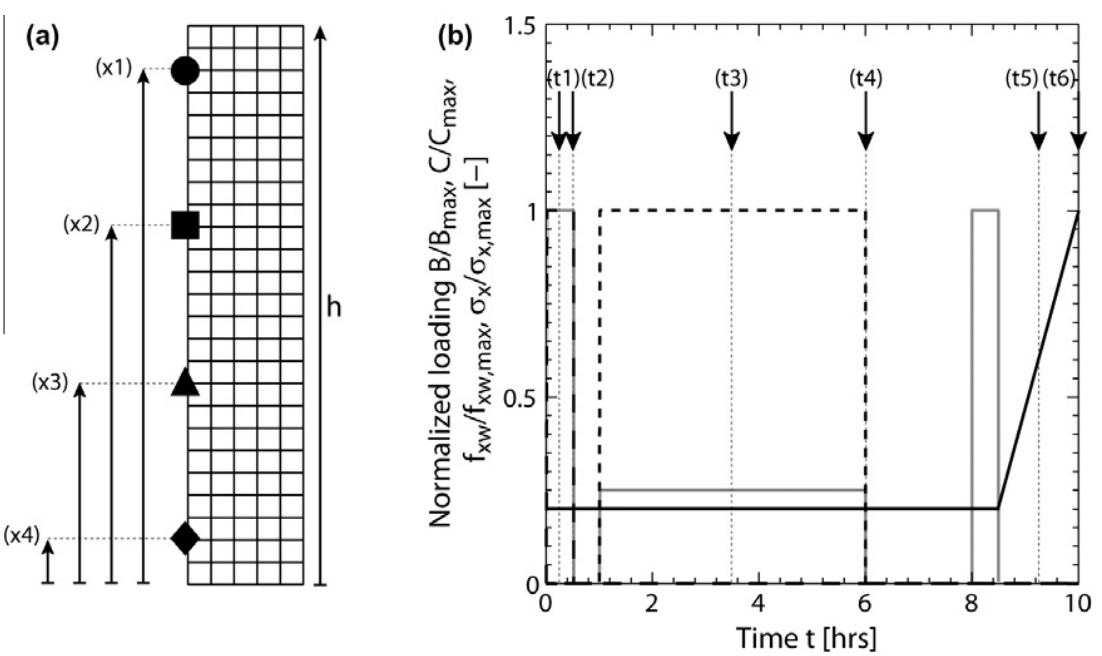

Fig. 6. Representation of simulation results: a. representative points at which the time evolutions are taken and b. representative times at which the profiles are taken.
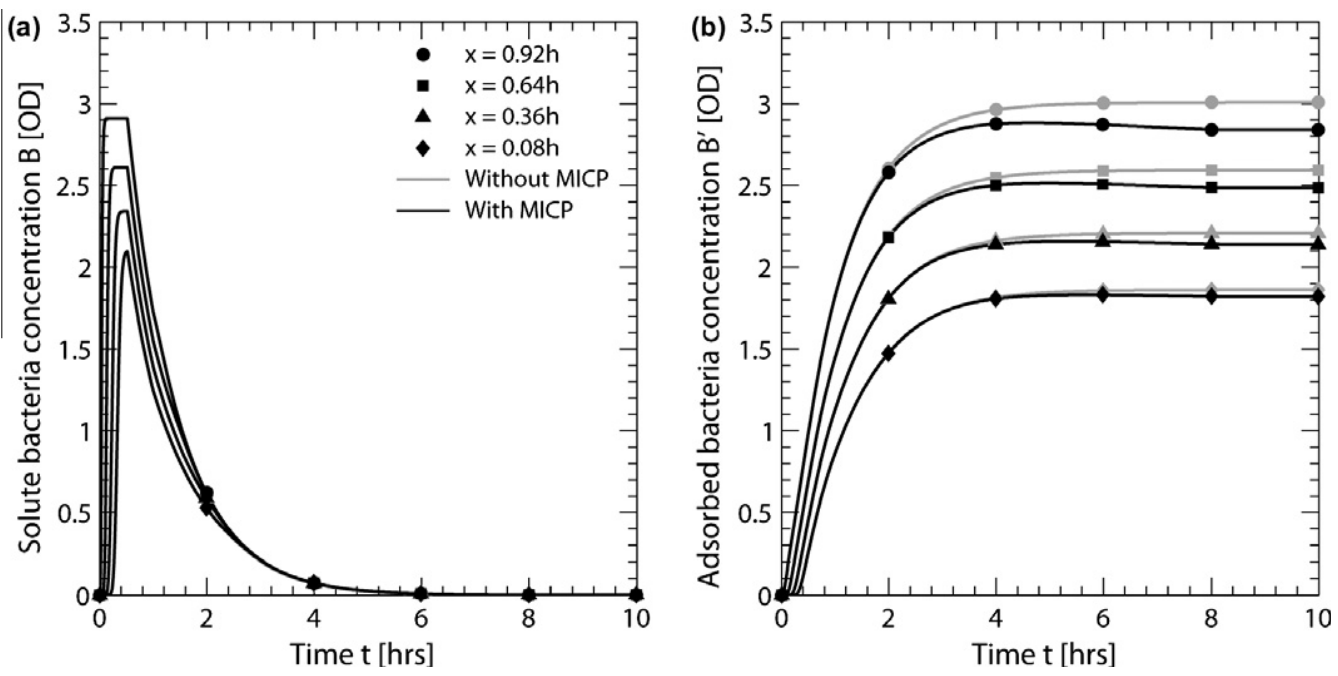

Fig. 7. Time evolution of the key bacterial variables: a. the solute bacterial concentration and b. the sorbed bacterial concentration.
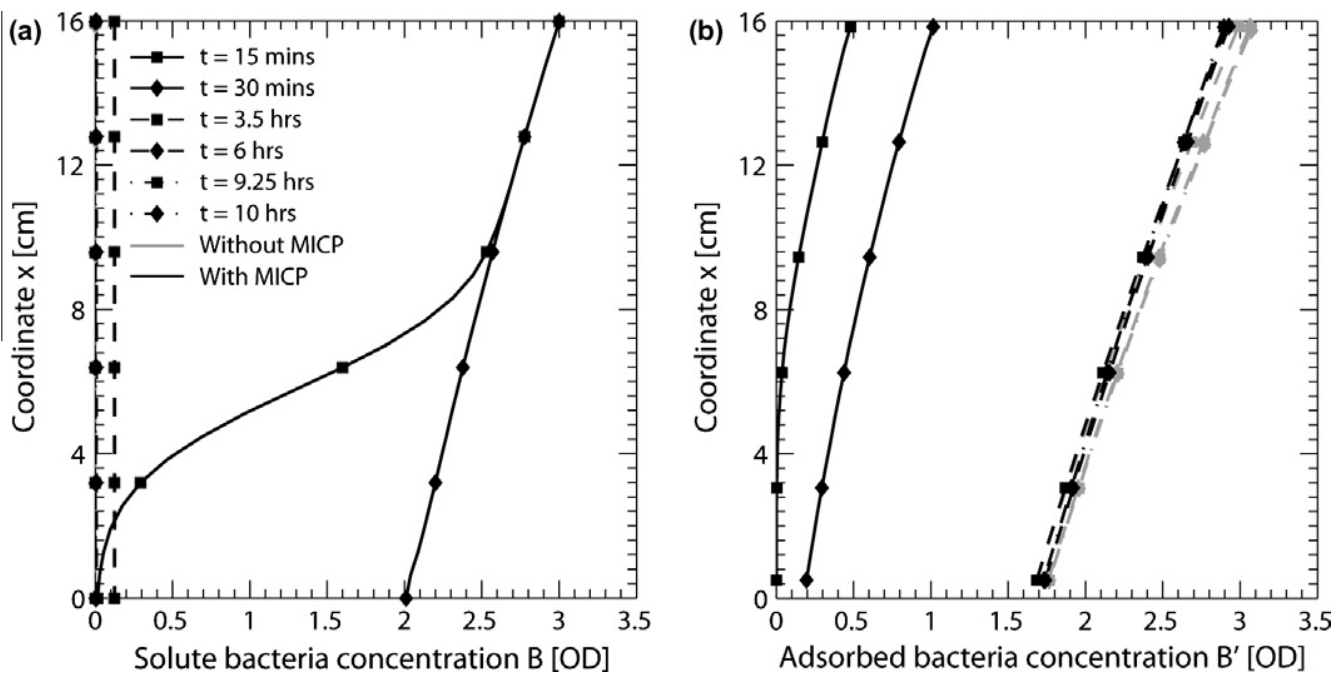

Fig. 8. Axial profiles of the key bacterial variables: a. the solute bacterial concentration and b. the sorbed bacterial concentration 

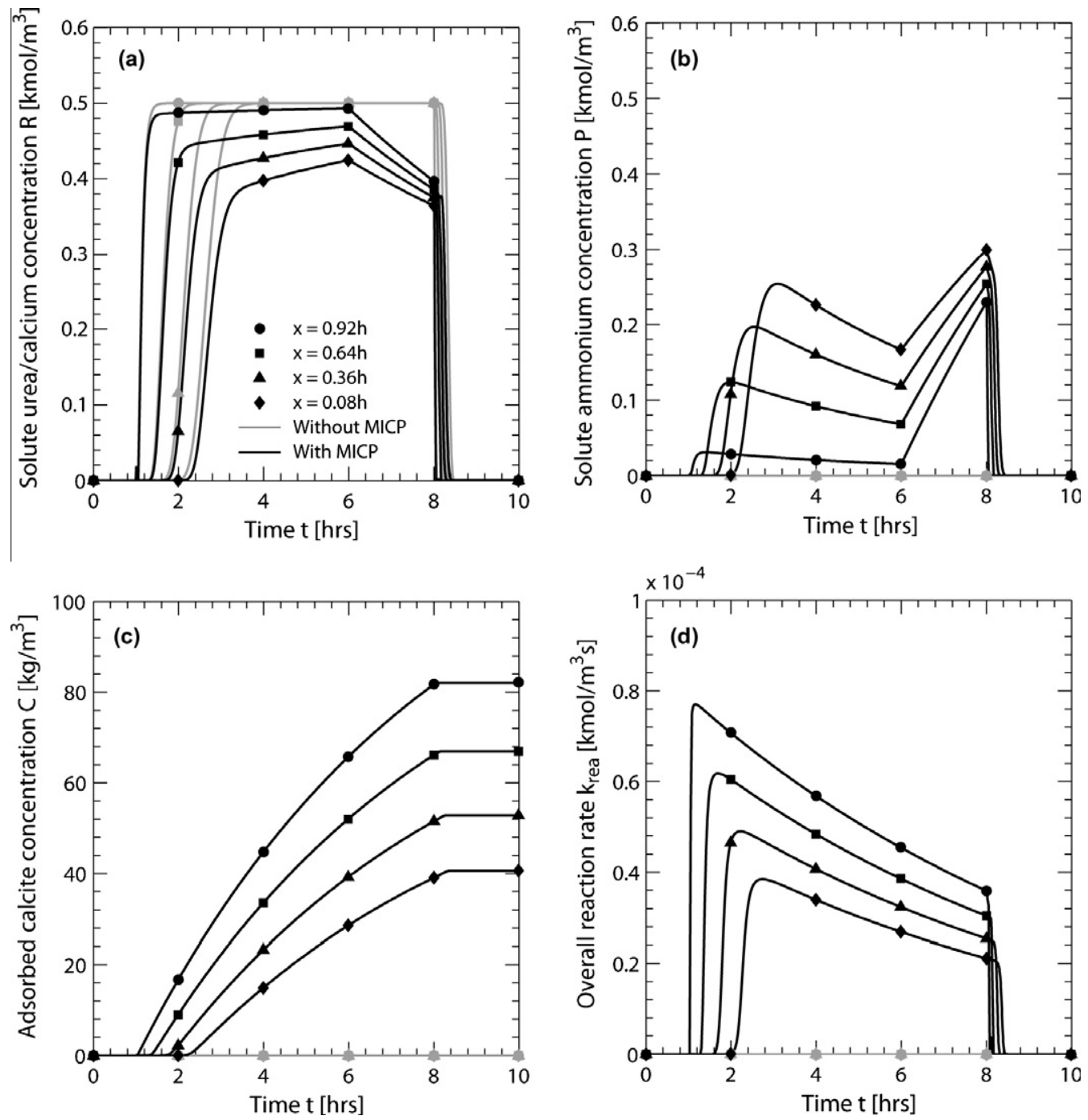

Fig. 9. Time evolution of the key chemical variables: a. the solute urea/calcium concentration, b. the solute ammonium concentration, c. the adsorbed calcite concentration and $\mathrm{d}$. the overall reaction rate.

values at specified points within the integration domain (integration points). If the meshes used for the $\mathrm{HM}$ and the $\mathrm{BC}$ problem are the same, the integration points coincide, and the results of each problem can be directly used in the other problem. However, if the meshes are different, the values of the variables of interest are interpolated according to Biver [33].

The final system of algebraic equations that describe the entire system and are implemented in the finite element code LAGAMINE is shown below.

$\left[\begin{array}{cc}\boldsymbol{S}+\theta \Delta t \boldsymbol{H} & \mathbf{Q}^{T} \\ \theta \Delta t \boldsymbol{Q} & 0\end{array}\right]_{n+\theta}\left\{\begin{array}{l}\tilde{\boldsymbol{p}}_{f} \\ \tilde{\boldsymbol{u}}_{s}\end{array}\right\}_{n+1}+\left[\begin{array}{cc}0 & 0 \\ 0 & \Delta t \widetilde{\boldsymbol{P}}\end{array}\right]_{n+\theta}$

$=\left[\begin{array}{cc}\boldsymbol{S}-(1-\theta) \Delta t \boldsymbol{H} & \mathbf{Q}^{T} \\ -(1-\theta) \Delta t \boldsymbol{Q} & 0\end{array}\right]_{n+\theta}\left\{\begin{array}{c}\tilde{\boldsymbol{p}}_{f} \\ \tilde{\boldsymbol{u}}_{s}\end{array}\right\}_{n}+\left\{\begin{array}{c}\Delta t \boldsymbol{f}_{p} \\ \Delta t \boldsymbol{f}_{u}\end{array}\right\}_{n+\theta}$

$\left[\begin{array}{ccc}\boldsymbol{M}_{b}+0.5 \Delta t \boldsymbol{K}_{b}+0.5 \Delta t \boldsymbol{L}_{b} & 0 & 0 \\ 0 & \boldsymbol{M}_{r}+0.5 \Delta t \boldsymbol{K}_{p}+0.5 \Delta t \boldsymbol{L}_{r} & 0 \\ 0 & 0 & \boldsymbol{M}_{p}+0.5 \Delta t \boldsymbol{K}_{p}+0.5 \Delta t \boldsymbol{L}_{r}\end{array}\right]_{n+\theta}$

$\left\{\begin{array}{c}\widetilde{\boldsymbol{B}} \\ \widetilde{\boldsymbol{R}} \\ \widetilde{\boldsymbol{P}}\end{array}\right\}_{n+1}=\left[\begin{array}{ccc}\boldsymbol{M}_{b}-0.5 \Delta t \boldsymbol{K}_{b}+0.5 \Delta t \boldsymbol{L}_{b} & 0 & 0 \\ 0 & \boldsymbol{M}_{r}-0.5 \Delta t \boldsymbol{K}_{p}+0.5 \Delta t \boldsymbol{L}_{r} & 0 \\ 0 & 0 & \boldsymbol{M}_{p}-0.5 \Delta t \boldsymbol{K}_{p}+0.5 \Delta t \boldsymbol{L}_{r}\end{array}\right]_{n+\theta}$

$\left\{\begin{array}{l}\widetilde{\boldsymbol{B}} \\ \widetilde{\boldsymbol{R}} \\ \widetilde{\boldsymbol{P}}\end{array}\right\}_{n}+\left\{\begin{array}{l}\Delta t \boldsymbol{f}_{b} \\ \Delta t \boldsymbol{f}_{r} \\ \Delta t \boldsymbol{f}_{p}\end{array}\right\}_{n+\theta}$

where $\boldsymbol{S}$ is the compressibility matrix; $\boldsymbol{H}$ is the permeability matrix; $\widetilde{\boldsymbol{P}}$ is the internal force vector; $\boldsymbol{Q}$ is the hydro-mechanical coupling matrix; $\boldsymbol{f}_{p_{f}}$ and $\boldsymbol{f}_{u_{s}}$ are the hydro-mechanical force vectors; $\boldsymbol{M}_{b}, \boldsymbol{M}_{r}$ and $\boldsymbol{M}_{p}$ are the bacterial and the chemical mass matrices; $\boldsymbol{K}_{b}, \boldsymbol{K}_{r}$ and $\boldsymbol{K}_{p}$ are the bacterial and the chemical stiffness matrices; $\boldsymbol{L}_{b}, \boldsymbol{L}_{r}$ and $\boldsymbol{L}_{p}$ are bacterial and chemical matrices and $\boldsymbol{f}_{b}, \boldsymbol{f}_{r}$ and $\boldsymbol{f}_{p}$ are the bacterial and the chemical force vectors.

Two finite element types are required to solve the equations based on the finite element formulation. A new type of element capable of simultaneously treating three degrees of freedom of concentration with both an exchange of information and different transport equation forms is developed. The new ADVEB elements are superposed to the existing MWAT elements of the finite element code LAGAMINE.

\section{Numerical analysis of typical features}

\subsection{Model description}

Model. The geometrical model of the column injection test consists of a vertical straight pipe with a length of $16 \mathrm{~cm}$ and a diameter of $6.6 \mathrm{~cm}$ (Fig. 4). The discretisation consists of an axisymmetric, homogeneous mesh composed of the superposed quadratic MWAT and ADVEB type finite elements. The soil parameters reported in Table 1 are representative of a silty sand and the transport properties are similar to those usually reported in the 


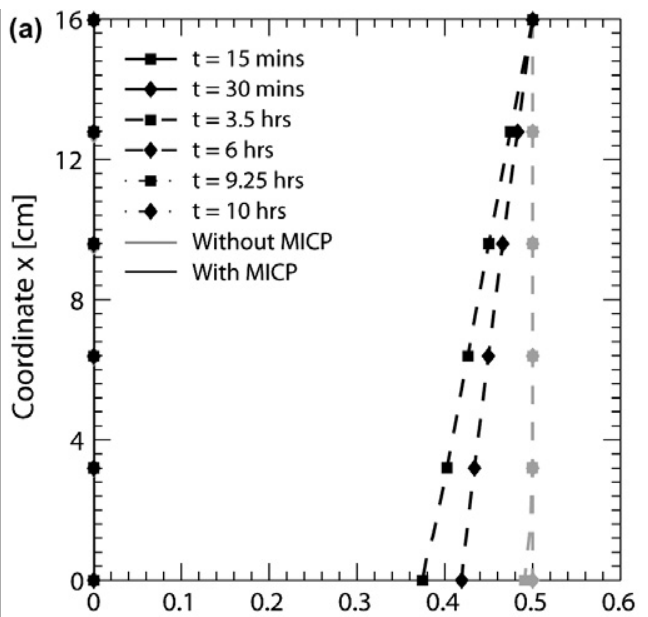

Solute urea/calcium concentration $\mathrm{R}\left[\mathrm{kmol} / \mathrm{m}^{3}\right]$

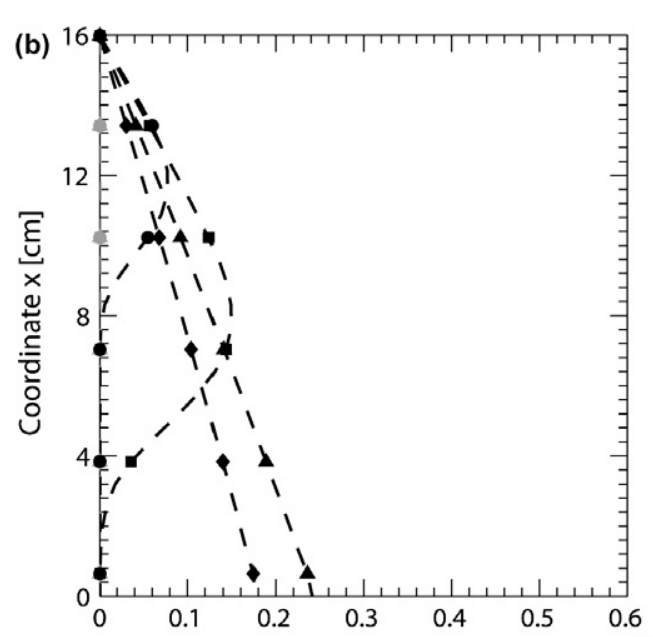

Solute ammonium concentration $\mathrm{P}\left[\mathrm{kmol} / \mathrm{m}^{3}\right]$
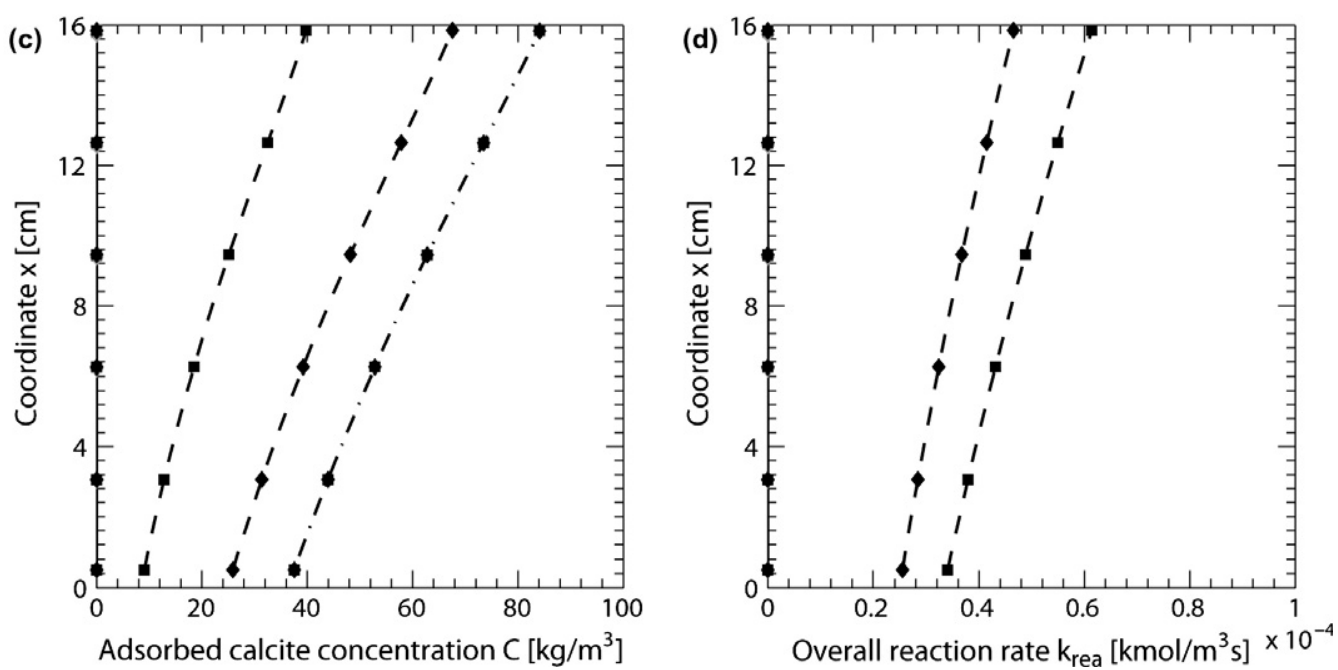

Fig. 10. Axial profiles of the key chemical variables: a. the solute urea/calcium concentration, b. the solute ammonium concentration, c. the adsorbed calcite concentration and $d$. the overall reaction rate.

literature. To focus on the main physical processes, minor processes have been neglected through the choice of parameters. The sorption of chemical species is neglected as this mechanism is assumed to play a minor role in sands and the bacterial attachment rate is considered constant. Furthermore, the decay of the bacteria is neglected over the time of this experience. Finally, the fluid density remains constant upon composition changes, so density driven flow is neglected in this simulation. The boundary conditions are shown in Fig. 4, with applied zero fluxes on the vertical boundaries. The BCHM initial conditions are assumed to be those of an undisturbed state. All of the concentrations are null, the pore water pressure is hydrostatically distributed and a vertical stress of $100 \mathrm{kPa}$ is applied on the top of the column in addition to the gravity loading.

Calculation. The bacteria are injected by a constant fluid flux imposed at the elements corresponding to the top of the column into the saturated sand sample. The concentrations of the bacteria or the urea/calcium are imposed at the corresponding nodes according to the test procedure. A mechanical loading is applied to the column after treatment. The gravity loading is considered in the simulation, and a $100-\mathrm{kPa}$ load is continuously applied to the top of the column.

The seven steps of the numerical simulation summarised in Fig. 5 are as follows:
(S1) Initialisation: a 100-kPa mechanical load and the gravity load are applied at the top of the column.

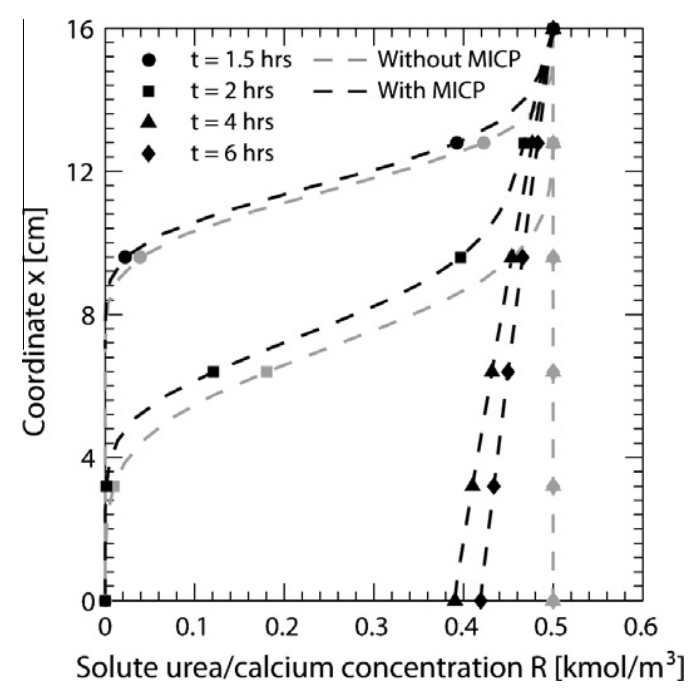

Fig. 11. Axial profiles of the solute urea/calcium concentration. 

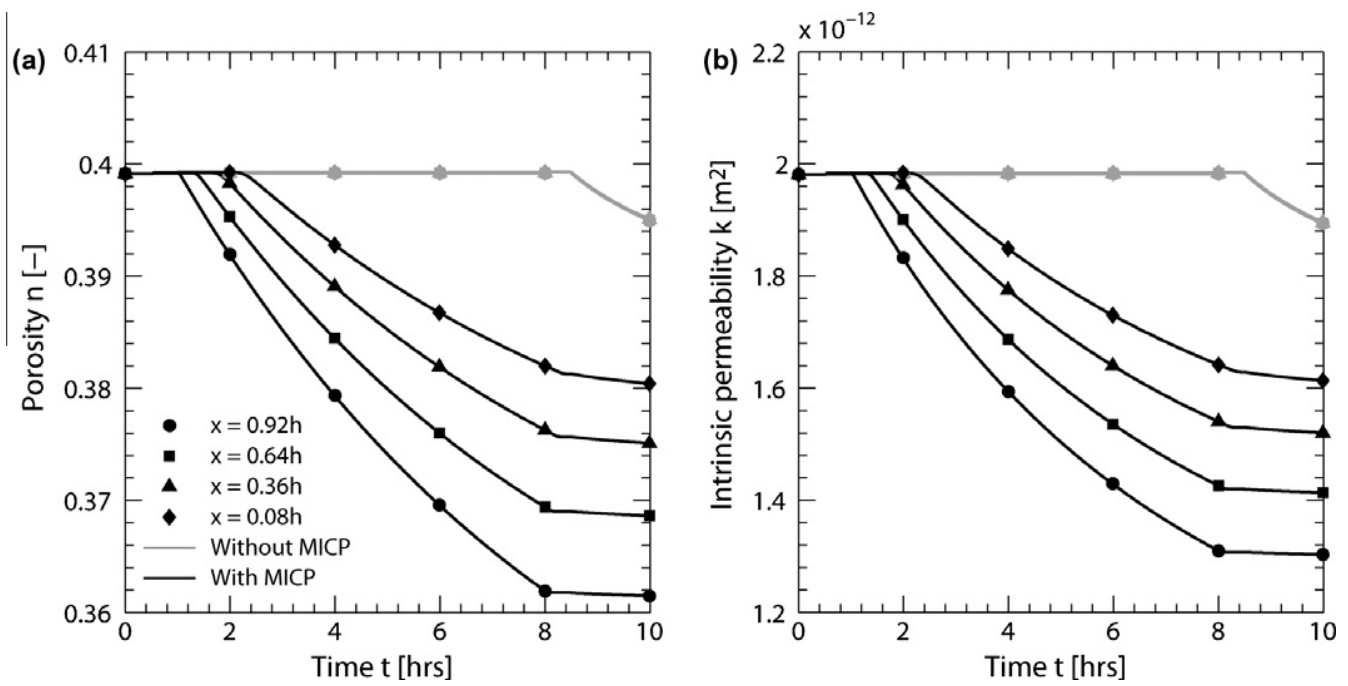

Fig. 12. Time evolution of the key hydraulic variables: a. the porosity and b. the intrinsic permeability.

(S2) Bacterial injection: the bacterial concentration is increased up to an optical density of 3 OD and held constant for 30 mins; a water flux of $10 \mathrm{ml} / \mathrm{min}$ is imposed simultaneously.

(S3) Setting: the system is closed to allow further bacterial attachment (30 min).

(S4) Chemical injection: the urea/calcium concentration is increased to $0.5 \mathrm{M}$ and held constant for $5 \mathrm{~h}$; a water flux of $2 \mathrm{ml} / \mathrm{min}$ is imposed simultaneously.

(S5) Setting: the system is closed to allow the chemicals to completely react $(2 \mathrm{~h})$.

(S6) Flushing: the system is rinsed with water to eliminate remaining solute species $(0.5 \mathrm{~h})$.

(S7) Mechanical loading: the vertical load is increased $(1.5 \mathrm{~h})$.

Two simulation types are compared to assess the main competing processes included in the modelling framework: a BCHM nonreactive simulation and a $\mathrm{BCHM}$ reactive simulation.

Results. To assess both the kinetics and the spatial variability of the processes, time evolutions at representative points and profiles at representative times have been plotted.

The time evolutions of key variables are plotted at four points distributed along the height of the column. The variables are taken at $0.92 \mathrm{~h}, 0.64 \mathrm{~h}, 0.36 \mathrm{~h}$ and $0.08 \mathrm{~h}$, according to Fig. $6 \mathrm{a}$. The profiles of the key variables are calculated at different times. These times (after $15 \mathrm{~min}, 30 \mathrm{~min}, 3.5 \mathrm{~h}, 6 \mathrm{~h}, 9.25 \mathrm{~h}$ and $10 \mathrm{~h}$ ) are representative of the loading steps. The characteristic times are plotted against the loading sequence in Fig. $6 \mathrm{~b}$.

\subsection{Simulation results}

\subsubsection{Bacterial response}

Fig. 7a displays the kinetics of the bacterial transport governed, in this simulation, by advection, hydrodynamic dispersion and sorption. In the absence of chemicals, the bacterial response is expected and verified to be identical in both the reactive and the nonreactive cases. After the chemical injection (after $1 \mathrm{~h}$ ), the porosity changes, the related permeability variations and the solid phase density changes have an almost negligible effect on the sorbed bacterial concentration (due to the flow-driven injection and the small column height). In Fig. 8a, the axial profiles of the solute bacteria concentration are reported. The spreading of the concentration front as a result of the bacterial dilution at the front can be observed in the figure. For a constant attachment rate, the concentration at the bottom of the column remains lower than the
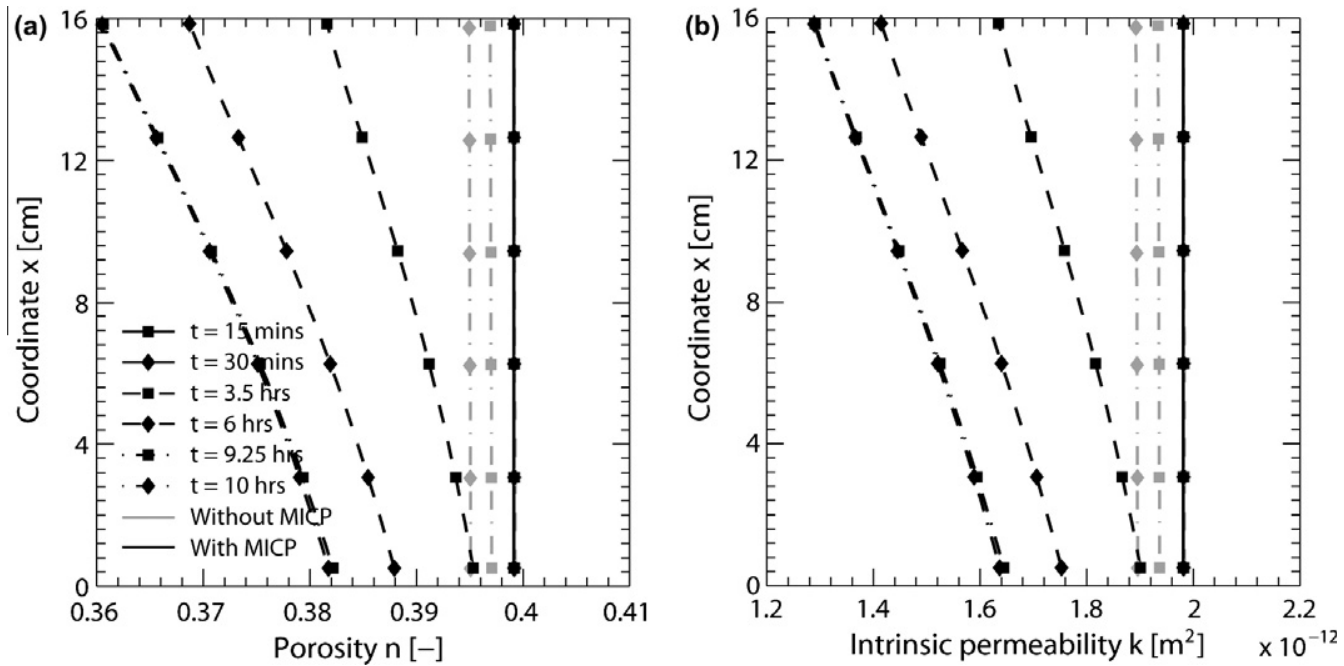

Fig. 13. Axial profiles of the key hydraulic variables: a. the porosity and b. the intrinsic permeability. 

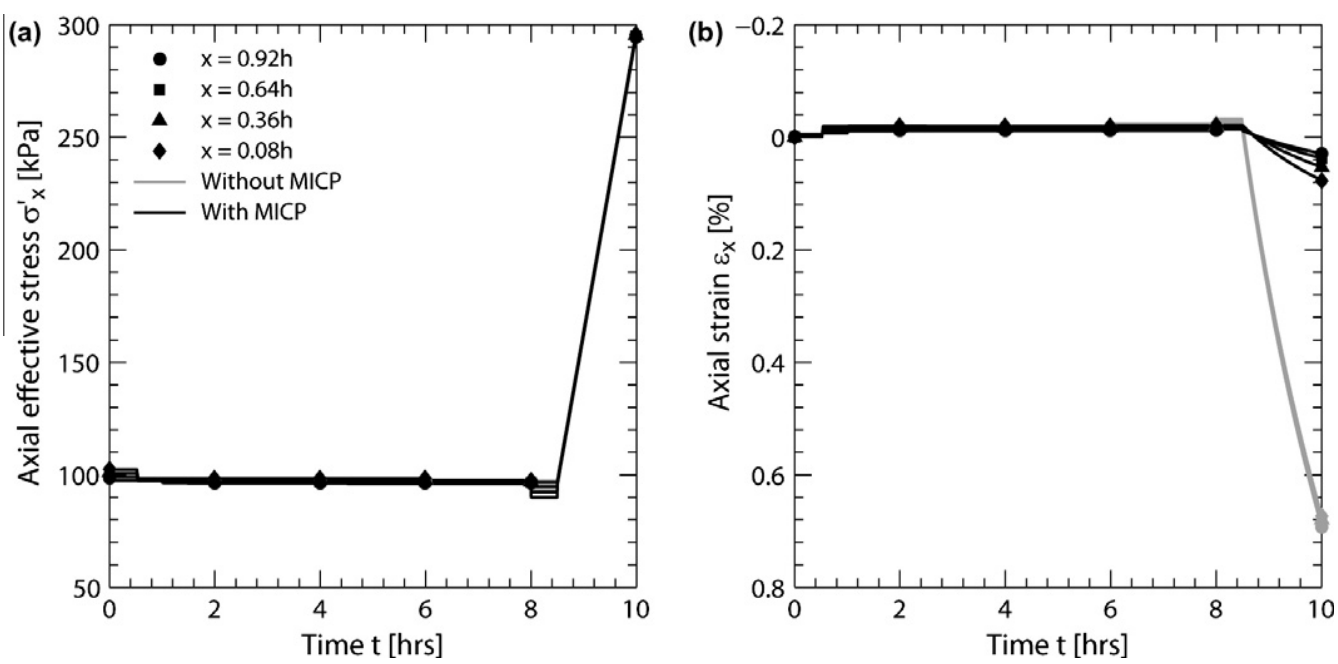

Fig. 14. Time evolution of the key mechanical variables: a. the axial effective stress and b. the axial strain.
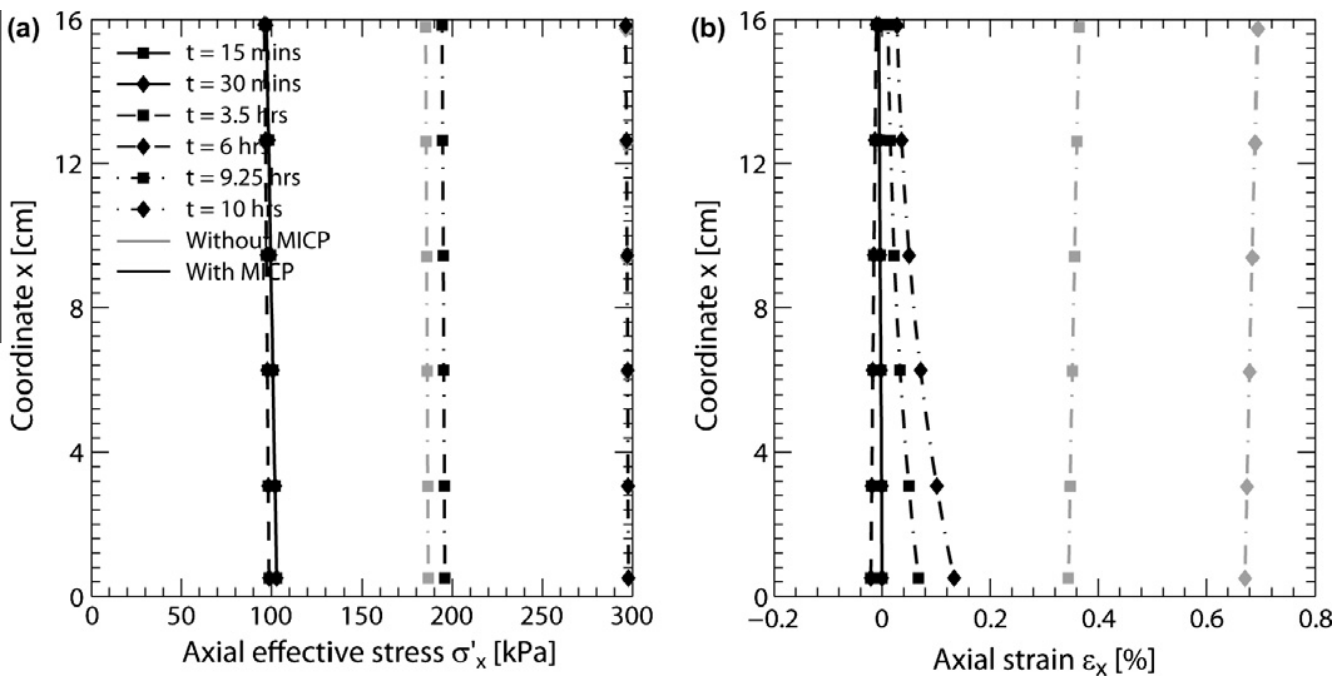

Fig. 15. Axial profiles of the key mechanical variables: a. the axial effective stress and b. the axial strain.

concentration near the injection point at all times, despite the progression of the front. A concentration gradient due to sorption appears to superpose the gradient due to advection. During the setting phase S3, the flow is prevented. The solute bacteria concentration is then strongly reduced due to the non-compensated sorption. During the chemical injection S4, the advective transport resumes and tends to compensate the concentration gradient due to sorption created during the bacterial injection and the setting phases S2 and S3, homogenising the concentration throughout the column. The bacteria simultaneously continue to attach to the solid surface, accelerating the reduction of the solute bacteria concentration.

The irreversible sorption of the bacteria (Fig. 7b) results in the build up of a bacterial concentration in the solid phase at a rate that is function of the constant attachment rate and the variable solute bacteria concentration. After the biologically induced chemical porosity changes $(1 \mathrm{~h})$, the concentration of adsorbed bacteria reduces as the mass (or amount) of bacteria remains constant (as shown in the non-reactive case) and the solid volume increases (the bacterial concentration in the solid phase is defined per unit volume of solid volume). The axial profile of adsorbed bacteria concentration in Fig. 8b reflects the solute concentration gradient formed during the bacterial injection phase S2. The axial profiles corresponding to phase S4 show that the setting phase S3, starting 30 min into the simulation, results in a major increase of the adsorbed bacterial concentration due to sorption in the absence of advection.

\subsubsection{Chemical response}

Fig. 9a provides a comparison between the evolution of the concentration of solute urea/calcium in the reactive and the non-reactive cases. In the most general case, the chemical transport is governed by advection, hydrodynamic dispersion, sorption and reaction. However, sorption of chemicals is neglected in this simulation. The chemical reaction causes a reduction in the urea/ calcium concentration with respect to that expected in a non-reactive case. In this case, the advective transport tends to balance the chemical consumption during the injection because there is a Dircihlet's boundary condition at the top of the column and the relative kinetics of the processes allow it (i.e., the advective flow rate is rather high with respect to the reaction rate). Once the injection is stopped and the drainage is prevented through the bottom during 
step S5, the molecules are fixed in space, and the evolution of the number of molecules of urea/calcium over time is uniquely controlled by the reaction rate. This faster concentration decrease can be observed between 6 and $8 \mathrm{~h}$ into the simulation. The concentration is additionally affected by the changes in the porosity, indicating a change in the fluid volume.

As observed for the bacterial transport, the urea/calcium concentration in Fig. 10a at the bottom of the column remains lower than that near the injection point at all times, despite the progression of the front. As the distance from the inlet increases, the chemical consumption becomes increasingly important because the reaction has had more time to progress. A concentration gradient due to reaction (similar to that due to sorption) superposes to the gradient due to advection. In this simulation, the latter only exists until the column is saturated in the non-reactive case (i.e., at $3 \mathrm{~h})$.

Fig. 10 shows the evolution of the axial profile of the solute ammonium concentration during the chemical injection phase S4. The shape of the chemical concentration front is defined by the hydrodynamic dispersion. The position of the front in the non-reactive case can be analytically verified because sorption is not considered for the chemical species. The front can be localised where $R=R_{\text {imp }} / 2=0.25 \mathrm{kmol} / \mathrm{m}^{3}$, and the fluid velocity is $2.43 \times 10^{-5} \mathrm{~m} / \mathrm{s}$. After $30 \mathrm{~min}$, the front should have reached axial coordinate $11.62 \mathrm{~cm}$. After $1 \mathrm{~h}$, the front should have reached axial coordinate $7.13 \mathrm{~cm}$. These simple calculations correspond well with the numerical front position, demonstrating that the advective transport process is correctly reproduced.

The solute ammonium (Fig. 9b) is a product of the overall biogrout reaction, the rate of which depends on the bacterial concentration, the solute urea/calcium concentration and time. Thus, its evolution over time can be correlated with the overall reaction rate and the fluid flow governing its advective transport. During the flow, the solute ammonium concentration tends to decrease with respect to its initial high value; this decrease corresponds to the maximum reaction rate due to the high flow rate. During setting phase $\mathrm{S} 5$, despite a reduced reaction rate, the chemically produced ammonium is not advected, and the concentration increases significantly. All of the solute ammonium is flushed out of the column during the rinsing.

The calcite (Fig. 9c) results from the precipitation following the overall reaction rate. The calcite concentration is defined per unit volume of solid phase, which increases with the precipitation and also affects the concentration. The calcite concentration increases non-linearly according to the non-linear reaction rate (Fig. 9d). An approximate analytical solution of the calcite precipitation can be sought to check the validity of the reactive model. Approximating linearly the decrease of the reaction rate between $1.2 \mathrm{~h}\left(k_{\text {rea }}=0.77 \times 10^{-4} \mathrm{kmol} / \mathrm{m}^{3} . \mathrm{s}\right)$ and $8 \mathrm{~h}\left(k_{\text {rea }}=0.35 \times 10^{-4} \mathrm{k}-\right.$ $\mathrm{mol} / \mathrm{m}^{3} \mathrm{~s}$ ), the total amount of calcite precipitated at coordinate $0.92 \mathrm{~h}$ assuming a mean porosity of 0.3805 (determined in Fig. 13a) is $84.2 \mathrm{~kg} / \mathrm{m}^{3}$. The numerical simulation yields a concentration of $82 \mathrm{~kg} / \mathrm{m}^{3}$. The relative error can be attributed to the overestimation of the reaction rate by the linear approximation.

The overall reaction rate is plotted against time in Fig. 9d. The overall reaction rate reaches its maximum at a given point as soon as the urea/calcium front reaches this point (at the beginning of phase S4). Beyond this point, the decreasing solute bacteria concentration combined with the constitutive time evolution of the reaction rate causes the rate to decrease to zero during step S6 upon the flushing of all of the solute components. (see Fig. 11).

\subsubsection{Hydraulic response}

Hydraulically, the porosity reduction (Fig. 12a) reduces the permeability (Fig. 12b) according to the Kozeny-Karman law. The mechanical component of the porosity reduction is dominant during phase S7. However, the main contribution is the chemical porosity variation during the chemical injection (S4), the setting phase (S5) and the start of the flushing phase (S6). The rate of the porosity variation decreases as the overall reaction rate decreases. The axial profiles of the porosity and the intrinsic permeability in Fig. 16a and b show that the kinetics of the competing processes involved in MICP result in a non-uniform distribution of the porosity and the permeability reductions. The boundary conditions and the geometry of the model are also key factors determining the final spatial distribution.

\subsubsection{Mechanical response}

The bio-chemo-hydraulic coupling changes the pore water pressure field due to the biologically induced calcite precipitation. These changes are small in this simulation due to the chosen boundary conditions. The effects on the axial effective stress field are thus negligible (Figs. 14 and 15a).

The bio-chemo-mechanical coupling is more evident in the mechanical response. The elastic stiffnesses are significantly increased, inducing a major reduction in the strains of the reactive case with respect to those of the non-reactive case (Figs. 14 and 15b). However, the mechanical reinforcement is not uniform throughout the column.

\section{Conclusions}

A theoretical and numerical framework for describing the interactions of the competing processes during MICP is presented. The mathematical formulation of the bio-chemo-hydro-mechanical model was obtained through a continuum approach by macroscopically expressing the mass conservation of the phases, the linear momentum conservation of the mixture and the mass conservation of the components according to a number of assumptions. The macroscopic constitutive equations necessary to complete the thermodynamic description of the material behaviour and link the dependent variables with the unknowns were then introduced while accounting for the relevant assumptions. The final set of field equations describing the system was obtained by combining the balance equations and the constitutive equations.

The finite element formulation of the system of coupled equations describing the problem was then derived. The equations describing the transport of the solute components were weighted with the Streamline Upwind Petrov Galerkin method, whereas the flow and the equilibrium equations were weighted with the classical Bubnov Galerkin method. The finite element formulation was implemented in a finite element code, requiring the development of a new type of finite element for multispecies reactive transport and the modification of the formulation of the existing finite elements describing the flow and the equilibrium. The coupling between the two element types was also introduced.

The ability of the model to reproduce the physical, the chemical and the biological processes considered in the theoretical framework was examined based on numerical examples. The flow-driven injection of bacteria and chemicals, followed by the mechanical loading, was simulated in a vertical column of sand. The loading sequence enabled the main model processes to be observed.

The results showed that the model was able to reproduce all of the mechanisms of interest and their couplings. Analytical methods were applied to verify the advective front propagation and the amount of calcite precipitation. Both of the phenomena were correctly reproduced with respect to the analytical solution. The simulation results highlighted the importance of the kinetics of the competing processes, the boundary conditions and the 
geometry in determining the final spatial distribution of the reinforcement in terms of porosity and permeability reduction, compressibility reduction and stiffness increase.

The use of this advanced coupled model for analysing the physical processes occurring during the injection of a reactive grout in a saturated, deformable porous media could be of great interest for the design of laboratory and in situ tests, as well as for in situ applications.

Finally, the model was developed to accommodate multispecies reactive transport in a deformable, porous media considering porosity, permeability and density changes. Thus, the model could easily be applied to a great number of applications by adapting the constitutive relations expressing the chemical reaction and its rate.

\section{Acknowledgment}

The authors would like to acknowledge the valuable work of Thibaud Meynet in the preliminary developments of the BCHM model.

\section{Appendix A}

\section{Balance equations.}

(AB1) The porous media is saturated with one fluid phase.

(AB2) The porous media is isothermal, all of the components and the phases are everywhere in thermal equilibrium, and temperature variations are not considered.

(AB3) The solid-fluid interface is a material surface with respect to the mass of the solid phase (i.e., despite the deformation and the movement of the boundary, no solid mass is transported across it; in other words, the fluid phase cannot penetrate inside the solid grains but always remains at the grain surface).

(AB4) The volume fractions of urea/calcium and ammonium in the solid phase are assumed to be negligible with respect to the solid grains, the bacteria and the calcite volumes.

(AB5) The fluid phase is considered perfectly miscible (i.e., its composition has no influence on its total volume).

(AB6) The net influx of chemical species in the solid and the fluid phases are negligible with respect to the sum of the net influx and the net production of bacteria and the net production of chemical species.

(AB7) The dispersive mass flux and the dispersive momentum flux of the phases are negligible with respect to their advective counterparts.

(AB8) The sum of the advective and the dispersive momentum fluxes of the fluid phase across the boundary is negligible with respect to the diffusive momentum flux of the same phase.

(AB9) The inertial forces are negligible with respect to the viscous forces.

(AB10) All of the components of a phase are assumed to be advected at the velocity of the phase.

(AB11) The dispersive and the diffusive mass fluxes are neglected for the components of the solid phase.

(AB12) No internal production of minerals or pore water occurs.

(AB13) All of the precipitated calcite is assumed to attach to the solid phase; therefore, no net influx is considered, and calcite is only present in its adsorbed solid form.

(AB14) The random mobility and the chemotaxis of bacteria is assumed to be negligible with respect to the advective and the non-advective fluxes.

(AB15) The gas production during MICP is neglected.

\section{Constitutive equations.}

(AC1) The advective flux is governed by Darcy's law.

(AC2) The non-advective fluxes obey Fick's law.

(AC3) The sorption of bacteria is assumed to be a first-order, kinetic, irreversible reaction.

(AC4) Growth is assumed to be negligible in the absence of nutrients.

(AC5) The decay of bacteria is assumed to be a first-order, kinetic, irreversible reaction, the rate of which is constant and equal in both the solid and the fluid phases.

(AC6) The sorption/desorption of urea/calcium and ammonium is assumed to be an equilibrium, reversible reaction governed by a linear equilibrium isotherm.

(AC7) The chemical reactions involved in the MICP are assumed to be a first-order, kinetic, irreversible reaction described by a bulk reaction rate that is governed by the available urease activity and the concentration of urea.

(AC8) Only the dissolved species react in the overall biogrout reaction.

(AC9) The urease of both the attached and the dissolved bacteria catalyse the overall biogrout reaction.

(AC10) The solid grains, the calcite and the bacteria are assumed to be incompressible.

(AC11) The fluid is assumed to be barotropic.

\section{References}

[1] Stocks-Fischer S, Galinat JK, Bang SS. Microbiological precipitation of CaCO3. Soil Biol Biochem 1999;31:1563-71.

[2] Whiffin VS. Microbial CaCO3 precipitation for the production of biocement. PhD thesis, School of Biological Sciences and Biotechnology, Perth, Murdoch University; 2004.

[3] Fritzges MB. Biologically induced improvement of the response of sands to monotonic loading. Master thesis, University of Massachusetts; 2005.

[4] Dejong JT, Fritzges MB, Nüsslein K. Microbially induced cementation to control sand response to undrained shear. J Geotech Geoenviron Eng 2006;132(11):1381-92.

[5] Rebata-Landa V. Bio-Mediated Geochemical Effects. PhD thesis, Georgia Institute of Technology; 2007.

[6] Whiffin VS, van Paassen LA, Harkes MP. Microbial carbonate precipitation as a soil improvement technique. Geomicrobiol J 2007;24:417-23.

[7] van Paassen LA. Biogrout: ground improvement by microbially induced carbonate precipitation. PhD thesis, TU Delft; 2009.

[8] Al Qabany A, Mortensen B, Martinez B, Soga K, DeJong J. Microbial carbonate precipitation: correlation of S-wave velocity with calcite precipitation. In: Han J, Alzamora DA, editors. Advances on geotechnical engineering. Proceedings of geo-frontiers, March 13-16, 2011. Dallas, Texas, USA: Geotechnical Special Publications; 2011.

[9] Burbank MB, Weaver TJ, Green TL, Williams BC, Crawford RL. Precipitation of calcite by indigenous microorganism to strengthen liquefiable soils. Geomicrobiol J 2011;28:301-12.

[10] Martinez BC, Barkouki TH, DeJong JD, Ginn TR. Upscaling of microbial induced calcite precipitation in 0.5 m columns: experimental and modeling results. In: Han J, Alzamora DA, editors. Advances on geotechnical engineering. Proceedings of geo-frontiers, March 13-16, 2011. Dallas, Texas, Proceedings of geo-frontiers, March 13-16
USA: Geotechnical Special Publications; 2011.

[11] van Wijngaarden WK, Vermolen FJ, van Meurs GAM, Vuik C. Modelling biogrout: a new ground improvement method based on microbial-induced carbonate precipitation. Transp Porous Media 2011;87(2):397-420.

[12] Bear J, Bachmat Y. Introduction to modeling of transport phenomena in porous media. Kluwer Acacdemic Publishers; 1991.

[13] Fauriel S, Laloui L. Constitutive modelling of MICP-treated soils. Géotechnique submitted for publication.

[14] Nemati M, Voordouw G. Modification of porous media permeability, using calcium carbonate produced enzymatically in situ. Enzyme Microb Technol 2003;33:635-42.

[15] Ivanov V, Chu J. Applications of microorganisms to geotechnical engineering for bioclogging and biocementation of soil in situ. Rev Environ Sci Biotechnol 2008;7:139-53.

[16] Bouchelaghem F, Vulliet L, Leroy D, Laloui L, Descoeudres F. Experimental study of a miscible grout through a deformable saturated porous media, and performances of advection-dispersion-filtration model. Int J Numer Anal Methods Geomech 2001;25:1149-73.

[17] Kühn M. Modelling feedback of chemical reactions on flow fields in hydrothermal systems. Surv Geophys 2009;30:233-51. 
[18] Bouchelaghem F, Vulliet L. Mathematical and numerical filtration-advectiondispersion model of miscible grout propagation in saturated porous media. Int J Numer Anal Methods Geomech 2001;25:1195-227.

[19] Saada Z, Canou J, Dormieux L, Dupla JC, Maghous S. Modelling of the cement suspension flow in granular porous media. Int J Numer Anal Methods Geomech 2005;29:691-711.

[20] Alaiwa AA, Saiyouri N, Hicher PY. Evaluation of grout concentration during grouting process based on convective dispersive flow model. In: Pande GN Pietruszczak S, editors. Numerical models in geomechanics. Proceedings of the 10th international symposium on numerical models in geomechanics, 2007. Rhodes, Greece: Taylor and Francis; 2007.

[21] Chupin O, Saiyouri N, Hicher PY. Modeling of a semi-real injection test in sand. Comput Geotech 2009;36:1039-48.

[22] Corapcioglu MY, Haridas A. Transport and fate of microorganisms in porous media: a theoretical investigation. J Hydrol 1984;72:149-69.

[23] Taylor SW, Jaffé PR. Substrate and biomass transport in porous medium. Water Resour Res 1990;26(9):2181-94.

[24] Clement TP, Peyton BM, Skeens RS, Jennings DA, Petersen JN. Microbial growth and transport in porous media under denitrification conditions: experiments and simulations. J Contam Hydrol 1997;24:269-85.

[25] Olson MS, Ford RM, Smith JR, Fernandez EJ. Mathematical modeling of chemotactic bacterial transport through a two-dimensional heterogeneous porous medium. Bioremed J 2006;10(1-2):13-23.

[26] Ding D. Transport of bacteria in aquifer sediment: experiments and modeling. Hydrogeol J 2010;18(3):669-79.

[27] Stumpp C, Lawrence JR, Hendry MJ, Maloszewski P. Transport and bacteria interactions of three bacterial strains in saturated column experiments. Environ Sci Technol 2011;45(6):2116-23.

[28] Schijven JF, Hassanizadeh SM. Removal of viruses by soil passage: overview of modeling, processes and parameters. Crit Rev Environ Sci Technol 2000;30(1):49-127.

[29] Schijven JF, Hoogenboezem W, Hassanizadeh SM, Peters JH. Modeling remova of bacteriophages MS2 and PRD1 by dune recharge at Castricum, Netherlands. Water Resour Res 1999;35(4):1101-11.

[30] Schijven JF, Hassanizadeh SM, De Bruin HAM. Two-site kinetic modeling of bacteriophages transport through columns of saturated dune sand. J Contam Hydrol 2002;57:259-79.

[31] Schijven JF, De Bruin HAM, Hassanizadeh SM, De Roda Husman AM Bacteriophages and clostridium spores as indicator organisms for removal of pathogens by passage through saturated dune sand. Water Res 2003;37:2186-94

[32] Torkzaban S, Hassanizadeh SM, Schijven JF, De Roda Husman AM. Virus transport in saturated and unsaturated sand columns. Vadose Zone 2006;5:877-85.
[33] Biver P. Etude phénoménologique et numérique de la propagation de polluants miscibles dans un milieu à porosité multiple. $\mathrm{PhD}$ thesis, Université de Liège, Liège, Belgium; 1993.

[34] Lichtner PC. Continuum model for simultaneous chemical reactions and mass transport in hydrothermal systems. Geochim Cosmochim Acta 1985;49:779-800.

[35] Steefel CI, DePaolo DJ, Lichtner PC. Reactive transport modeling: an essential tool and a new paradigm for the earth sciences. Earth Planet Sci Lett 2005;240:539-58.

[36] Yeh GT, Tripathi VS. A critical evaluation of recent developments in hydrogeochemical transport models of reactive multichemical components. Water Resour Res 1989;25(1):93-108.

[37] Steefel CI, Lasaga AC. A coupled model for transport of multiple chemica species and kinetic precipitation/dissolution reactions with application to reactive flow in single phase hydrothermal systems. Am J Sci 1994:294(5):529-92.

[38] Xu T, Pruess K. Modeling multiphase non-isothermal fluid flow and reactive geochemical transport in variably saturated fractured rocks: 1 . Methodology. Am J Sci 2011;301:16-33.

[39] Spycher NF, Sonnenthal EL, Apps JA. Fluid flow and reactive transport around potential nuclear waste emplacement tunnels at Yucca Mountain, Nevada. J Contam Hydrol 2003;62-63(0):653-73.

[40] Panday S, Corapcioglu MY. Reservoir transport equations by compositional approach. Transp Porous Media 1989;4:369-93.

[41] Loret B, Gajo A, Simoes FMF. A note on the dissipation due to generalized diffusion with electro-chemo-mechanical couplings in heteroionic clays. Eur ] Mech Solids 2004;23:763-82.

[42] Rubin J. Transport of reacting solutes in porous media: relation between mathematical nature of problem formulation and chemical nature of reactions. Water Resour Res 1983;19(5):1231-52.

[43] Terzaghi C. The shearing resistance of saturated soils and the angle between the planes of shear. In: 1st International conference on soil mechanics and foundation engineering, vol. 1; 1963. p. 54-56.

[44] Charlier R. Approche unifiée de quelques problèmes non linéaires de mécanique des milieux continus par la méthode des éléments finis (grandes déformations des métaux et des sols, contact unilatéral de solides, conduction thermique et écoulements en milieu poreux). PhD thesis, Université de Liège, Liège, Belgium; 1987.

[45] Collin F. Couplages thermo-hydro-mécaniques dans les sols et les roches tendres partiellement saturés. PhD thesis, Université de Liège, Liège, Belgium; 2003. 